Al】I03 431420

United States Department of Commerce

National Institute of Standards and Technology

NIST

PUBLICATIONS

NIST Technical Note 1281

\title{
The NIST Digitally Synthesized Power Calibration Source
}

N. M. Oldham, O. B. Laug, B. C. Waltrip, and R. H. Palm

$-Q C$

100

.05753

\#1281

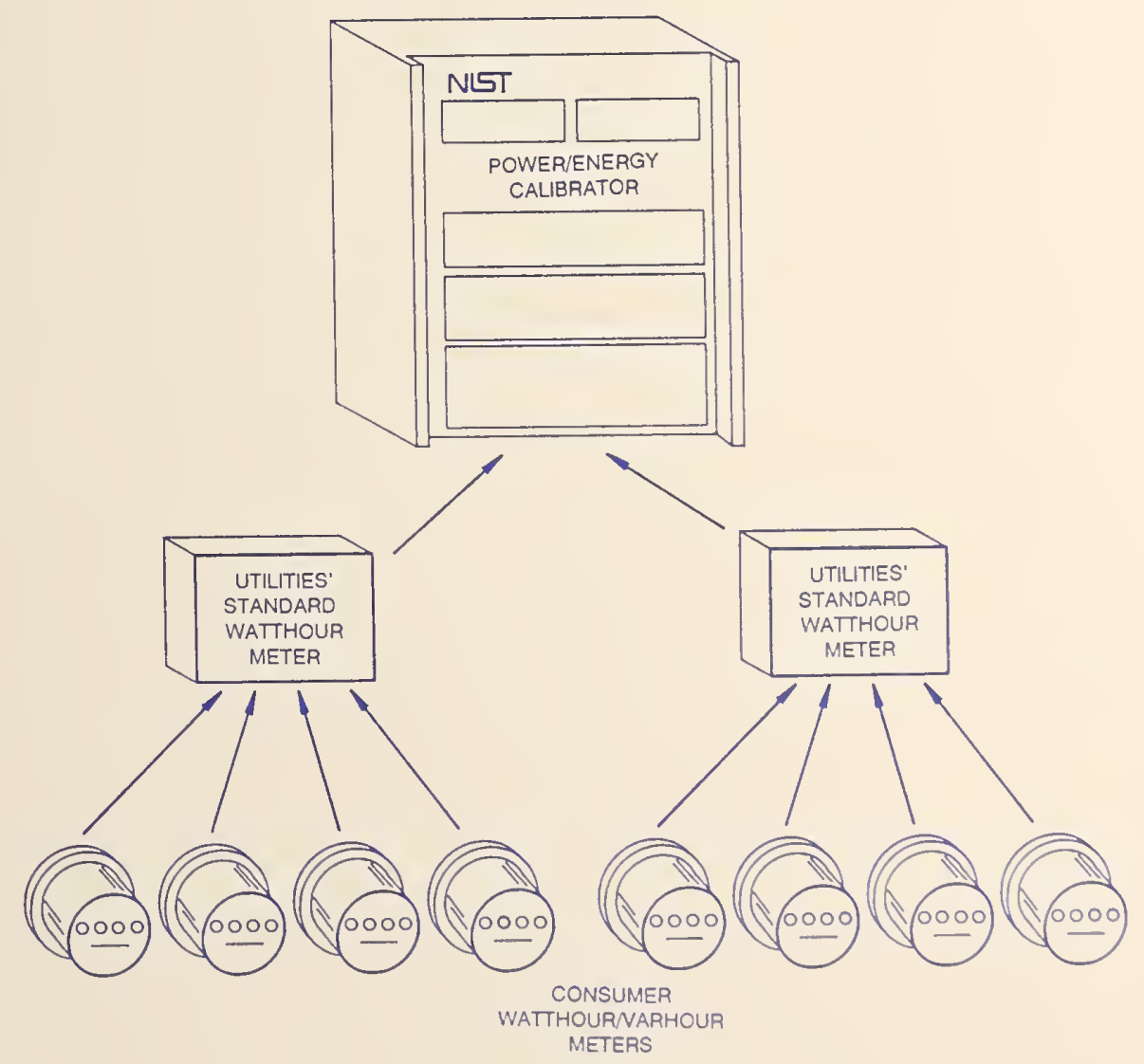

1990

C. 2 
NATIONAL INSTITUTE OF STANDARDS : TECHNOLOGY

Research Information Center

Gaithersburg, MD 20899 


\section{NIST Technical Note 1281}

\section{The NIST Digitally Synthesized Power Calibration Source}

N. M. Oldham

O. B. Laug

B. C. Waltrip

R. H. Palm

Electronic Instrumentation and Metrology Group Electricity Division

National Institute of Standards and Technology

Gaithersburg, MD 20899

August 1990

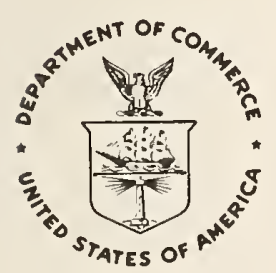

U.S. Department of Commerce

Robert A. Mosbacher, Secretary

National Institute of Standards and Technology John W. Lyons, Director 
National Institute of Standards and Technology

Technical Note 1281

Natl. Inst. Stand. Technol.

Tech. Note 1281

62 pages (Aug. 1990)

CODEN: NTNOEF
U.S. Government Printing Office

Washington: 1990
For sale by the Superintendent of Documents U.S. Government Printing Office Washington, DC 20402 
List of Figures

List of Tables

1. INTRODUCTION . . . . . . . . . . . . . . . . . . . . . . . .

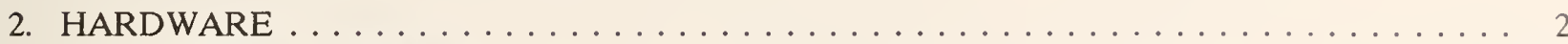

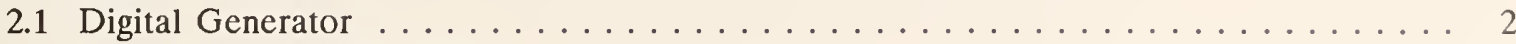

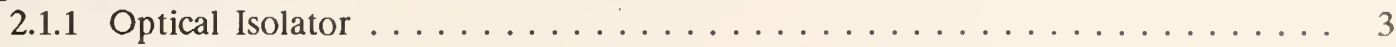

2.1 .2 Interface . . . . . . . . . . . . . . . . . . . 3

2.1 .3 Memories ........................... 3

2.1.4 Digital-to-Analog Converters . . . . . . . . . . . . . . . . 7

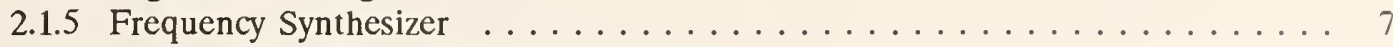

2.1.6 Power Supply and Rear Panel Wiring . . . . . . . . . . . . . . . 7

2.1.7 Board Location and Back Plane . . . . . . . . . . . . . . . . . 11

2.2 Voltage Amplifier . . . . . . . . . . . . . . . . . . . . 12

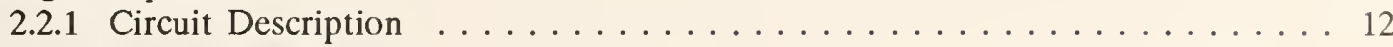

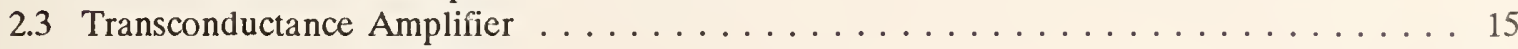

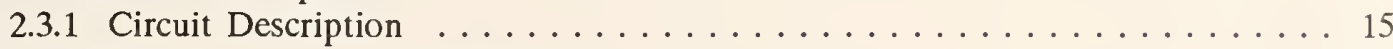

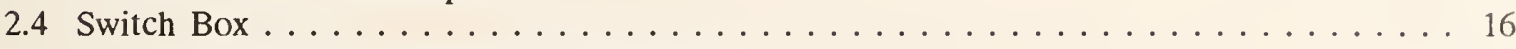

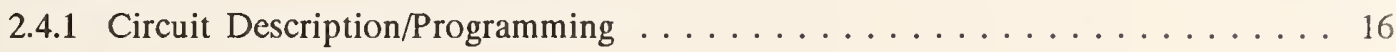

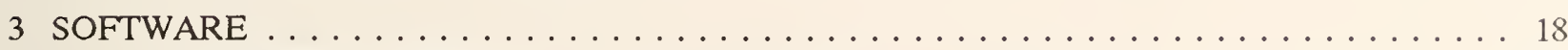

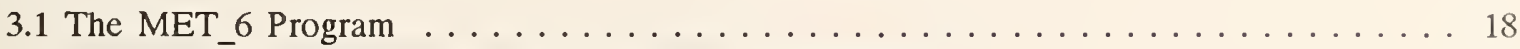

3.2 Software Considerations Based on System Configuration . . . . . . . . . . . 18

3.2.1 Switch Box vs. no Switch Box . . . . . . . . . . . . . . . . 18

3.3 Generator Control Routines . . . . . . . . . . . . . . . . . . . . 19

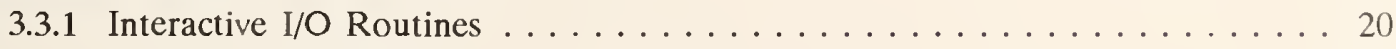

3.3.1.1 Amplitude . . . . . . . . . . . . . . . . . . . . 20

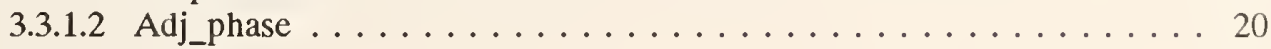

3.3 .1 .3 Cor_dac . . . . . . . . . . . . . . . . . . 21

3.3.1.4 Synth_load ....................... 22

3.3.2 Subprograms to Perform Specific Generator Control Tasks . . . . . . . . . 22

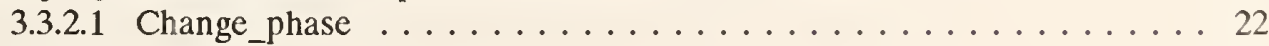

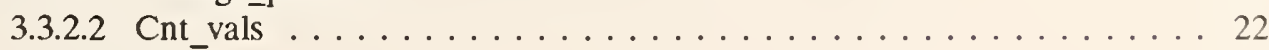

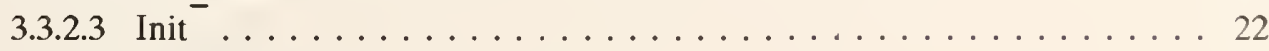

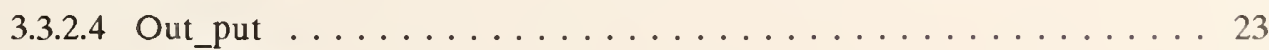

3.3 .2 .5 Process_key . . . . . . . . . . . . . . . . 23

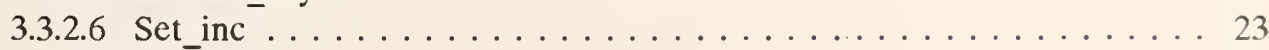

3.3 .2 .7 Status . . . . . . . . . . . . . . . . . 23

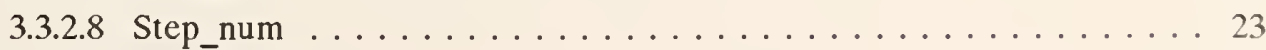

3.3.2.9 Wav_gen . . . . . . . . . . . . . . . . . 23

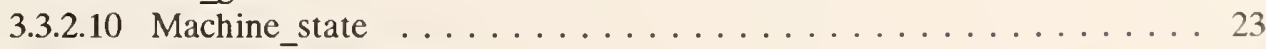

3.4 Generator Characterization Subprograms . . . . . . . . . . . . . 24

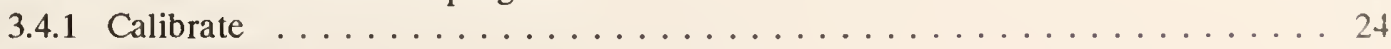

3.4 .2 Compliance . . . . . . . . . . . . . . . . . . 25

3.4 .3 Measure . . . . . . . . . . . . . . . . . . . . 25

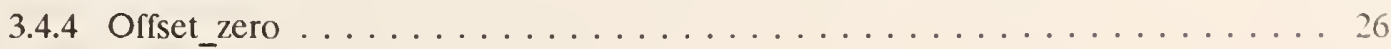


3.5 Subprograms useful for Power/Energy Calibrations $\ldots \ldots \ldots \ldots \ldots \ldots \ldots \ldots \ldots$

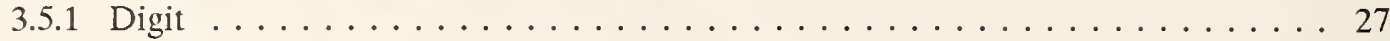

3.5 .2 Guildline . . . . . . . . . . . . . . . . . . . 29

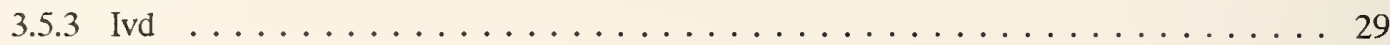

3.5 .4 Switch . . . . . . . . . . . . . . . . . . . 29

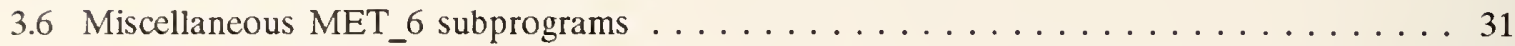

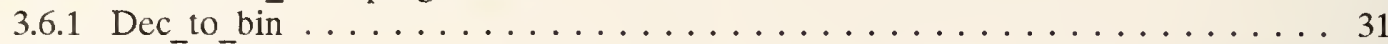

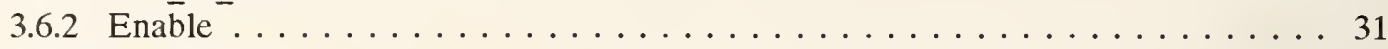

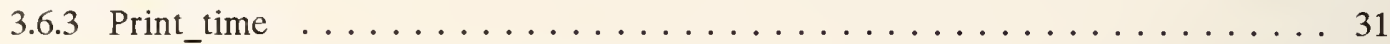

4. GENERATOR OUTPUT BOARD ADJUSTMENT $\ldots \ldots \ldots \ldots \ldots \ldots \ldots \ldots \ldots \ldots$

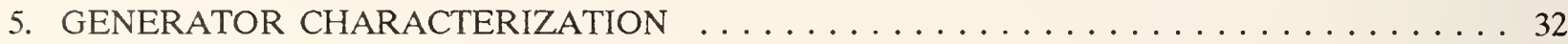

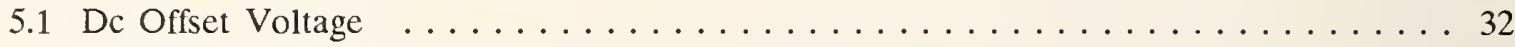

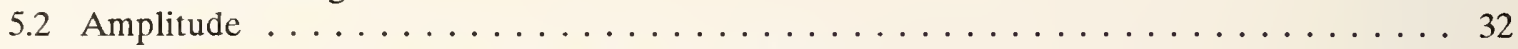

5.3 Transconductance Amplifier Compliance Voltage . . . . . . . . . . . . . 32

6. SYSTEM PERFORMANCE AND CONCLUSIONS $\ldots \ldots \ldots \ldots \ldots \ldots \ldots \ldots \ldots$

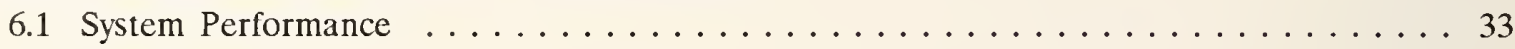

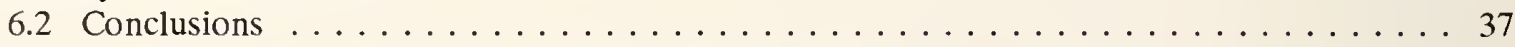

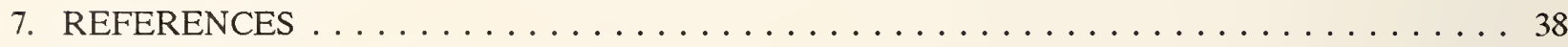

APPENDIX A: Table of Met_6 Variables . . . . . . . . . . . . . . . . . . . . . . . 39 
Figure 1. Block diagram of the power calibration source.

Figure 2. A digitally synthesized waveform.

Figure 3. Block diagram of the dual-channel digital generator. 3

Figure 4. Optical isolator board. $\quad 4$

Figure 5. Interface board. 5

$\begin{array}{llr}\text { Figure 6. } & \text { Memory board. } & 6\end{array}$

$\begin{array}{llr}\text { Figure 7. DAC board. } & 8\end{array}$

$\begin{array}{llr}\text { Figure 8. Frequency synthesizer board. } & 9\end{array}$

Figure 9. Rear panel GPIO connections and power supply connector. 10

Figure 10. Cambion cardcage slots showing generator board locations. 11

Figure 11. Generator back plane wiring. 11

Figure 12. Complete circuit diagram of the precision voltage amplifier.

$\begin{array}{ll}\text { a. Amplifier circuit. } & 13\end{array}$

b. Control and overload protection circuitry. 14

Figure 13. Complete circuit diagram of the transconductance amplifier. 15

$\begin{array}{ll}\text { Figure 14. Complete circuit diagram of the switch box. } & 17\end{array}$

Figure 15. Basic relationships of various routines in the MET_6 program. 19

Figure 16. Residual voltage and current integral nonlinearity after gain corrections. 33

Figure 17. Voltage and current differential nonlinearity around $120 \mathrm{~V}$ and $5 \mathrm{~A}$. 34

Figure 18. Phase differential nonlinearity - generator angle vs change in power 35 indication of a TDM wattmeter at zero power factor.

Figure 19. Long term stability of the source voltage, current, and phase angle as 35 measured by a thermal wattmeter.

Figure 20. Maximum differences between the power calibration source and the power 36 bridge using a TDM wattmeter as a transfer standard.

Figure 21. Maximum differences between the power calibration source and the power 36 bridge after correcting for the current drift. 


\section{List of Tables}

page

Table 1. Settings for System Configuration Variables 18

Table 2. Switch Box Program Codes 30 


\title{
THE NIST DIGITALLY SYNTHESIZED POWER CALIBRATION SOURCE
}

\author{
N. M. Oldham, O. B. Laug, B. C. Waltrip \\ and R. H. Palm \\ National Institute of Standards and Technology \\ Electricity Division \\ Electronic Instrumentation and Metrology Group \\ Gaithersburg, MD 20899
}

\begin{abstract}
A digitally synthesized source of "phantom" power for calibrating electrical power and energy meters is described. Independent sources of voltage, current, and phase angle are programmable between $0-240$ volts, $0-5$ amperes, and $0-360$ degrees, respectively. The uncertainty of the active and reactive power is estimated to be within $\pm 100 \mathrm{ppm}$ of the full scale apparent power (volt-amperes).
\end{abstract}

Key Words: calibration, digital waveform synthesis, power measurement, TDM wattmeter, transconductance amplifier, voltage amplifier, wattmeter, watt-hour meter.

\section{INTRODUCTION}

Calibration of wattmeters and watthour meters has traditionally been made by comparing the meter under test (MUT) to a standard wattmeter or watthour meter. The advantage of that approach is that a precise knowledge of the source parameters is not required. Voltage and current amplitudes and the phase angle between them need only be known approximately and the stability of each of these parameters is not critical as long as the power or energy output of the MUT is averaged or integrated over the identical period as that of the standard instrument. With the advent of multifunction instruments capable of measuring voltage, current, power factor, and active and reactive power, a knowledge of each of the source parameters has become advantageous. The measurement of reactive power and energy, in particular, is greatly simplified if the source of voltage, current, and phase angle is known and stable.

This approach has led to the development of a dual-channel sinewave source of voltage and current, which is shown in figure 1. Previous experience with digital waveform synthesis methods [1-6] provided the basis for designing a precision digital waveform generator to synthesize two low-level sinusoidal signals, which are programmable in both amplitude and phase angle. An illustration of a 20 -step digitally synthesized signal, and the sine wave from which the sampled points were derived, is given in figurc 2 . A special voltage amplifier A1 [7] was designed to scale the low-level voltage $\mathrm{V}_{1}$ to typical test levels ranging from 60-240 V, while test currents ranging from 1-5 A are obtained with a spccially designcd transconductance amplifier A2 [8]. The source is controlled by a desk-top computer that is linked to auxiliary instrumentation for measuring the analog and digital outputs of the MUT. ${ }^{1}$

1 In order to describe adequately the systems and tests discussed in this report, commercial equipment and instruments are identified by manufacturer's name and/or model number. In no case does such identification imply recommendation or endorsement by the National Institute of Standards and Technology, nor does it imply that the material or equipment identified is necessarily the best available for the purpose. 
The controller for the power calibration source is a Hewlett Packard 9836 desk-top computer equipped with one megabyte of memory, a general purpose input/output (GPIO) interface card, and a DMA card. Data is transmitted and received at the generator rear panel through the 50-line GPIO cable (see HP 98622A GPIO Interface Installation manual for pin connections).

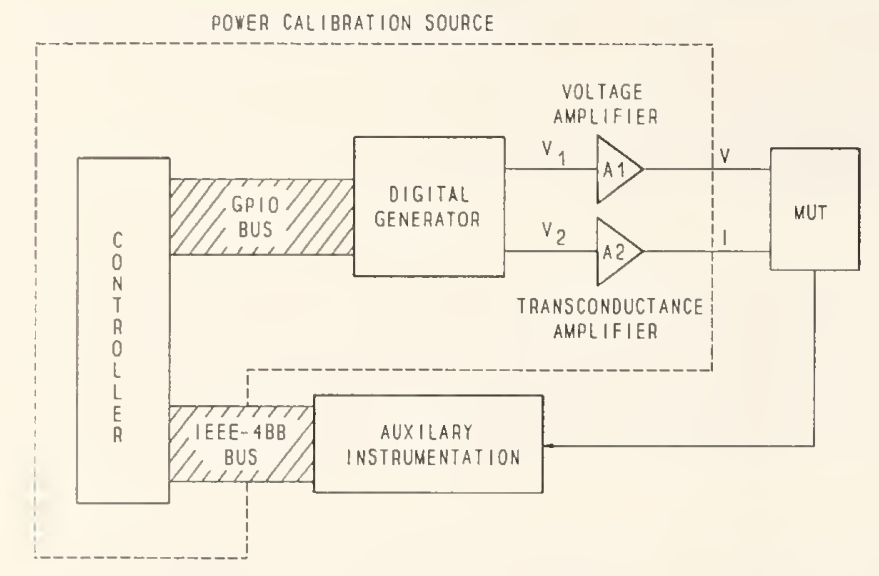

Figure 1. Block diagram of the power calibration source.

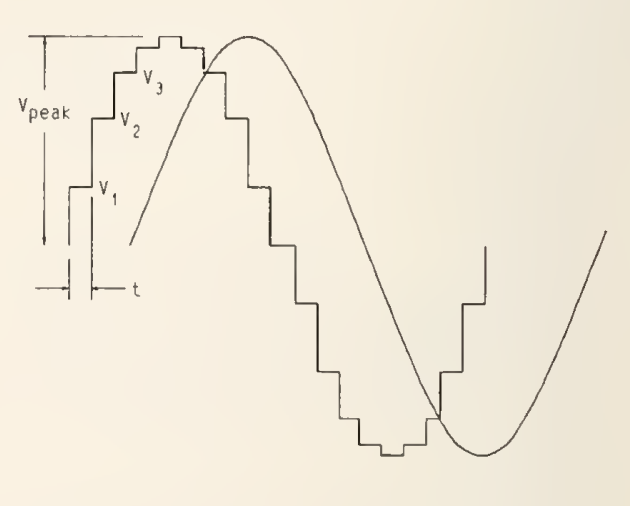

Figure 2. A digitally synthesized waveform.

\section{HARDWARE}

\subsection{Digital Generator}

The heart of the power calibration source is a digital generator (see fig. 3), which synthesizes voltages $\mathrm{V}_{1}$ and $\mathrm{V}_{2}$ in a staircase or "zero-order-hold" approximation to a sinusoidal waveform. Two signals whose waveforms are independently programmable are constructed by sequentially applying digital values stored in random access memories, RAM1 and RAM2 to 18-bit multiplying digital-to-analog converters, MDAC1 and MDAC2. The values stored in memory are equally spaced samples of this waveform with up to 2048 discrete steps per period. For normal operation the stored functions are sinewaves; however, any arbitrary waveforms with up to 1024 harmonic components may be stored. The phase angle between the two waveforms is determined by changing the set of function values stored in RAM2.

The theoretical resolution of the phase angle separating a pair of digitally synthesized sinewaves is a function of the resolution of the processor used to calculate the sample points, the resolution of the generating DACs (this determines to what extent each step is quantized), and the number of steps (sample points) per period. The algorithm used to calculate the sample points is performed with adequate precision in the computer to introduce negligible errors. The generating MDACs, capable of 18-bit precision, are normally used as 16-bit converters to speed up data transmission. These MDACs may be updated at $1 \mu \mathrm{s}$ intervals, and at $60 \mathrm{~Hz}, 2048$ steps are used to synthesize one period. The angular resolution under these conditions (based on computer simulations) is approximately one microradian [9].

The amplitudes of $\mathrm{V}_{1}$ and $\mathrm{V}_{2}$ may be set independently between $0-10$ volts-peak by controlling the dc reference voltages supplied to MDAC1 and MDAC2 with a second pair of 18-bit DACs. This technique provides an amplitude resolution of approximately $38 \mu \mathrm{V}\left(10 / 2^{18}\right.$ volts). The offsets of all four DACs may be adjusted remotely over a range of $\pm 500 \mathrm{ppm}$ by employing four additional 8-bit DACs. This technique provides a means for trimming the dc offset and gain of each of the generated waveforms that is adjustable under software control. 


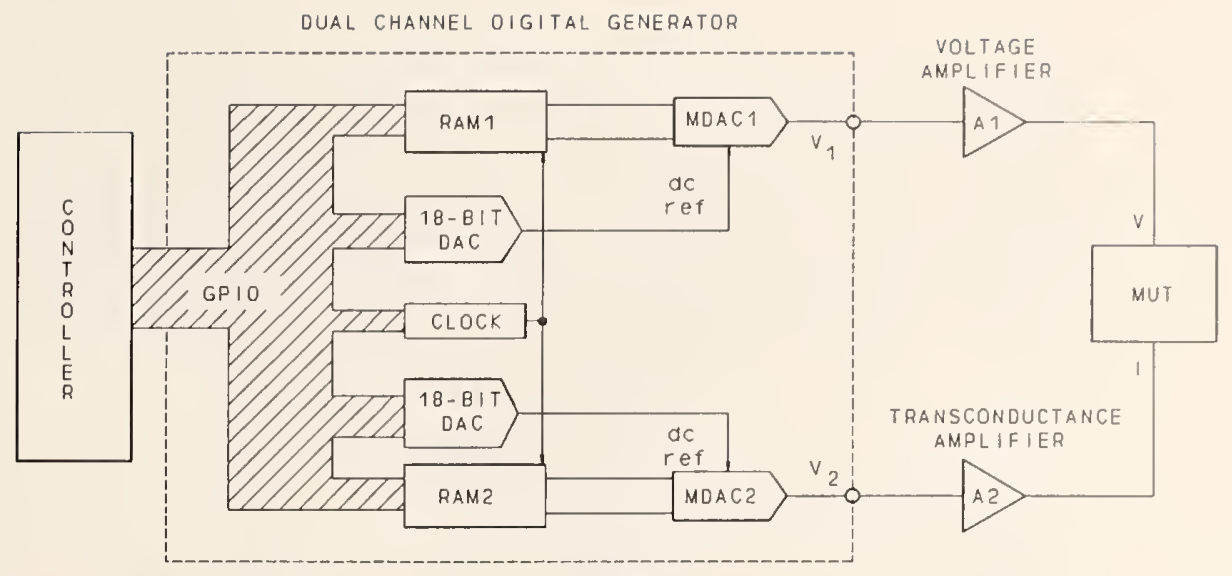

Figure 3. Block diagram of the dual-channel digital generator.

The frequency of the generated waveforms is a function of the number of steps per period and the sample rate (for a $60 \mathrm{~Hz}$ sine wave with 2048 steps the sample rate is $122.88 \mathrm{kHz}$ ). A programmable frequency synthesizer is used to generate the clock signal, which provides the strobe pulse for each sample point. It has a short-term stability of approximately 1 part in $10^{8}$.

A detailed description of the digital generator hardware is given below. Note that figure 3 is a simplified diagram that does not include some of the hardware discussed below.

\subsubsection{Optical Isolator}

Data from the HP GPIO passes through the Optical Isolator Board (fig. 4) to separate the generator ground from the computer ground. Since the generator is a "listener," only the GPIO output lines and the handshake signal lines PCTL, PFLG, and CTLO are optically isolated. The HP 2630 (U1. U8, U12) optical isolators invert the data, which is restored to the correct polarity with inverting buffers (U9-U11). The PFLG, which originates at the generator (and is the only outgoing line), is isolated separately in U13. The 5-volt power supply used to terminate the GPIO lines is a Datel dc-dc converter mounted on the board.

\subsubsection{Interface}

Once isolated, the data is decoded in the Interface Board (fig. 5). The GPIO data is separated into a "data" bus and a "control" bus which steers the data to the appropriate board. Whenever the GPIO data is changed, the PCTL line is pulled high (about $1 \mu \mathrm{s}$ after the data is valid). Data is latched into U1 and $\mathrm{U} 2$ by this PCTL line when CTL0 is high. When CTLO goes low, the output buffers U6-U9 are enabled, placing the control word on edge connector pins 3-18.

The PFLG, which is normally low, is pulsed high for $1 \mu$ s (time set by R1 and one-shot U4), about $1 \mu \mathrm{s}$ (set by R2 and C1) after the positive edge of PCTL. This logic provides a timed handshake with the GPIO interface, holding the data on the data bus (edge connector pins 38-53) for $1 \mu \mathrm{s}$.

\subsubsection{Memories}

The sample point values of the generated waveforms are stored in random access memory (RAM) located on the Memory Board (fig. 6). GPIO data is transferred from edge connector pins 21-28 (most 


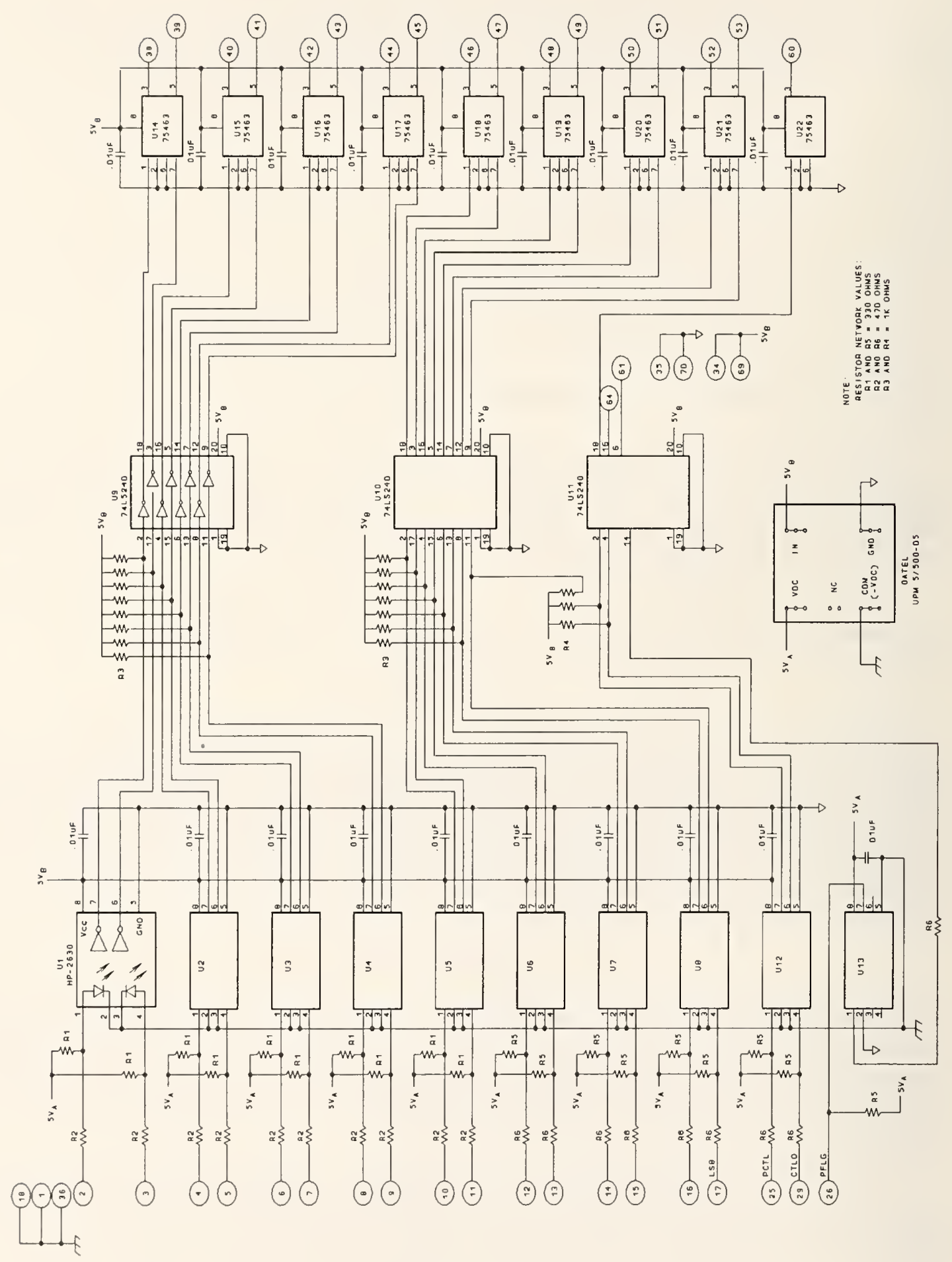

Figure 4. Optical isolator board. 


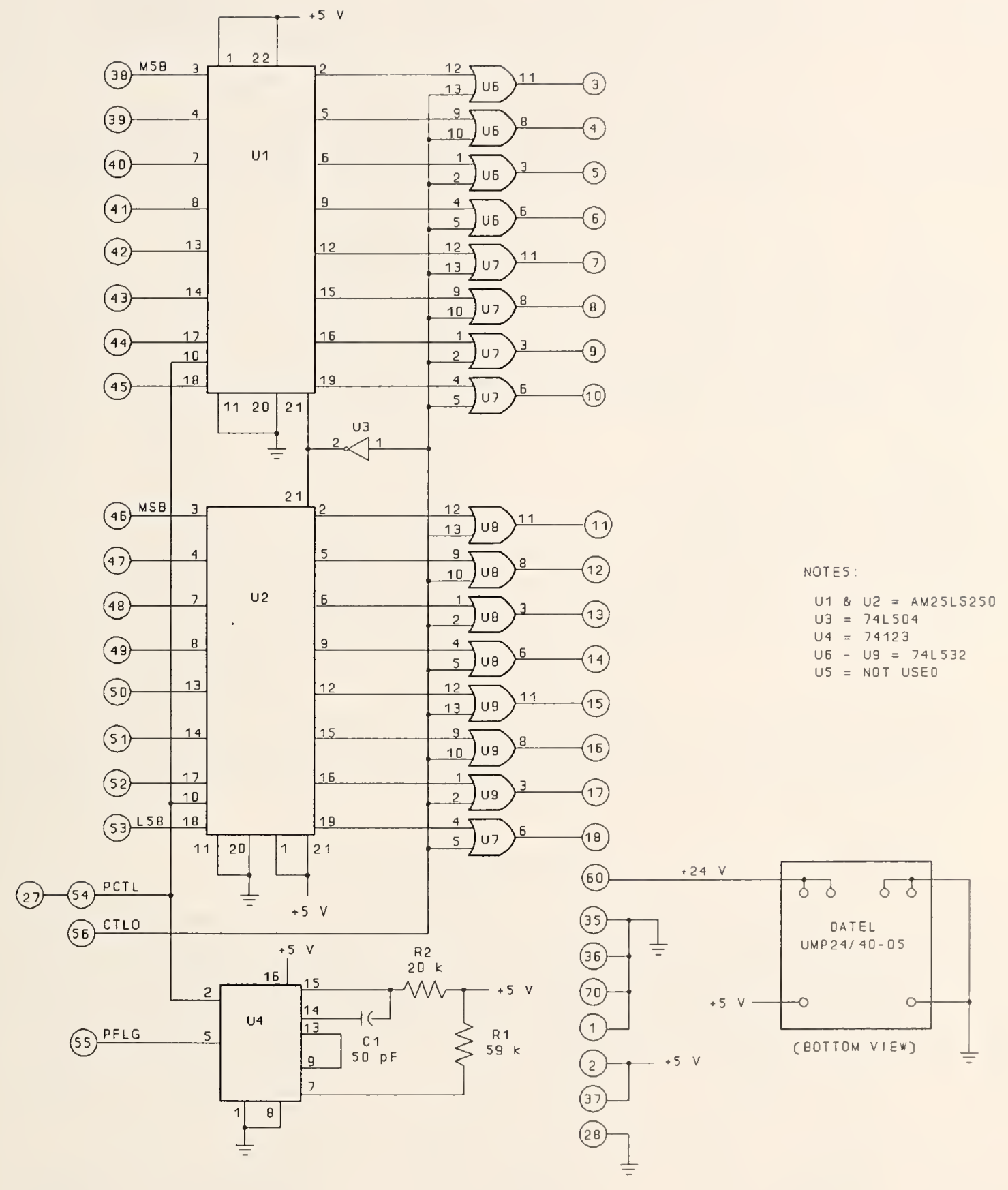

Figure 5. Interface board. 


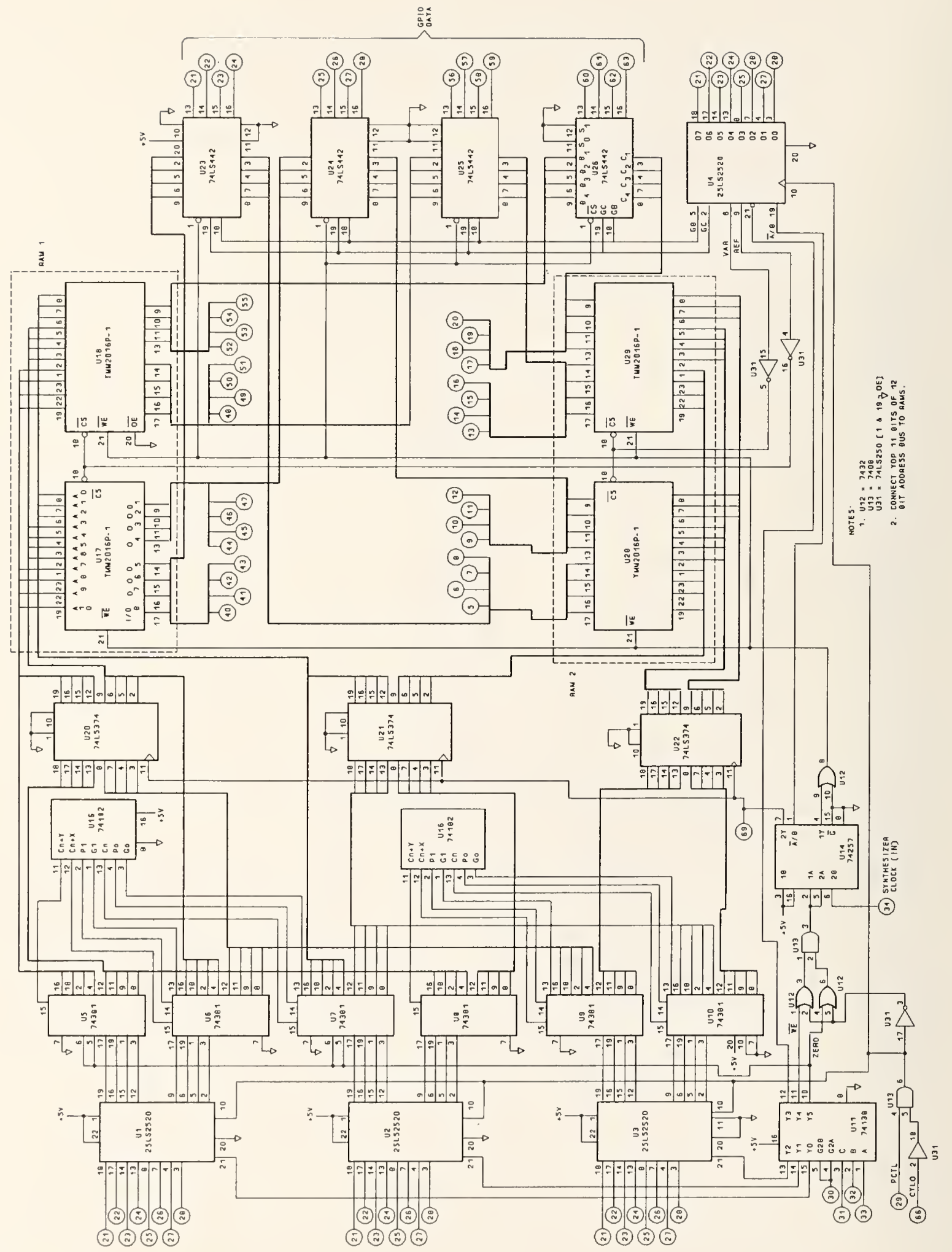

Figure 6. Memory board. 
significant 8 bits) and 56-63 (least significant 8 bits) through transceivers U23-U26 to the data lines of the reference channel RAM1 (U17,U18) and the variable channel RAM2 (U28,U29). The transfer path and the RAM chip selects are latched into $\mathrm{U} 4$ before the data is transmitted, and the RAM write enable signals are derived from the PCTL signal through U12-U14. Addresses for RAM1 are generated in the addresscounter circuit (U1,U2,U5,U6,U7,U15,U20 and U21) which is driven either from PCTL (during loading) or the synthesizer clock (during operation). Similarly, U2,U3,U8,U9,U10,U16,U21 and U22 comprise the address counter for RAM2.

Each memory holds 2048 16-bit words, and the waveforms can be constructed from all or a binary fraction of the 2048 data values. The selection of steps is made by programming the appropriate bits into $\mathrm{U} 1, \mathrm{U} 2$ and $\mathrm{U} 3$ to increment the address counters by $2^{\mathrm{n}}$ where $\mathrm{n}$ can vary from $0-11$.

\subsubsection{Digital-to-Analog Converters}

The waveforms stored in RAM1 and RAM2 are converted to low-level voltage waveforms in the digital-to-analog converter (DAC) Boards - one for each output channel (fig. 7). Data to generate the waveform appears at edge connector pins 40-57 and are latched into U1,U2 (for 16 bits) and U3 (for 18 bits) by the SYNTH CLK line. Multiplying digital-to-analog converter (MDAC) U8 converts the data word to a corresponding voltage level within a maximum swing of \pm 10 volts. U10, an optional buffer amplifier, boosts the output current from $\pm 10 \mathrm{~mA}$ to $\pm 100 \mathrm{~mA}$.

The output waveform amplitude is adjustable from 0 - 10 volts-peak by adjusting the dc reference to MDAC U8 (pins 24,25) between 0 - 10 volts-dc. The amplitude resolution of MDAC U9 used for this adjustment is 18 bits, and this data is loaded in 8-bit bytes into latches U4,U5,U6 from data on edge connector pins 5-12. The data in these latches is converted to a de voltage in MDAC U9 and amplifier U2. Two edge connections, REF IN and INTERNAL REF, are provided on the board so that an external reference may be used to generate MDAC U9's reference voltage. If no external reference is available, the INTERNAL REF pin must be connected to the REF IN pin.

The dc-offsets for both U8 and U9 are programmable through U11 (a dual 8-bit DAC) and U13 (dual operational amplifiers), which provide dc-offset adjustment of about $\pm 250 \mathrm{ppm}$ of full scale amplitude. The resistors connected to pins 2 and 6 of U13 convert the unipolar 10-volt outputs to bipolar \pm 5 -volt outputs.

\subsubsection{Frequency Synthesizer}

The system clock pulse, used to control waveform generation by latching new data into each DAC Board, originates in the Frequency Synthesizer Board (fig. 8). This is a composite, two-piece board that uses a commercial frequency synthesizer (Syntest model SM-102 with 51/2 digit resolution) and a decoder/latch board, which holds the 5-BCD digits and the 3-bit frequency range data. The data is held in latches U1,U2 and U3, which are enabled for loading by U4. The Syntest board has been modified (voltage regulators removed) so that it will operate with $+5 \mathrm{~V}$ and $+15 \mathrm{~V}$ power supplies instead of the original $+5 \mathrm{~V}$ and $+24 \mathrm{~V}$ supplies.

\subsubsection{Power Supply and Rear Panel Wiring}

The generator requires one 5-volt, 5-ampere power supply for the digital circuitry and one \pm 15 volt, 1 -ampere power supply for the analog circuitry. These supplies are connected to the analog and digital hardware through an Amphenol connector as shown in figure 9. Pin connections for the rear panel GPIO connectors are also shown in this figure. The 50-pin connector attaches to the controller, while the 24pin IEEE-488 type connector provides optically isolated GPIO-data to the SWITCH BOX (described in 2.4) and other peripheral devices as needed. 


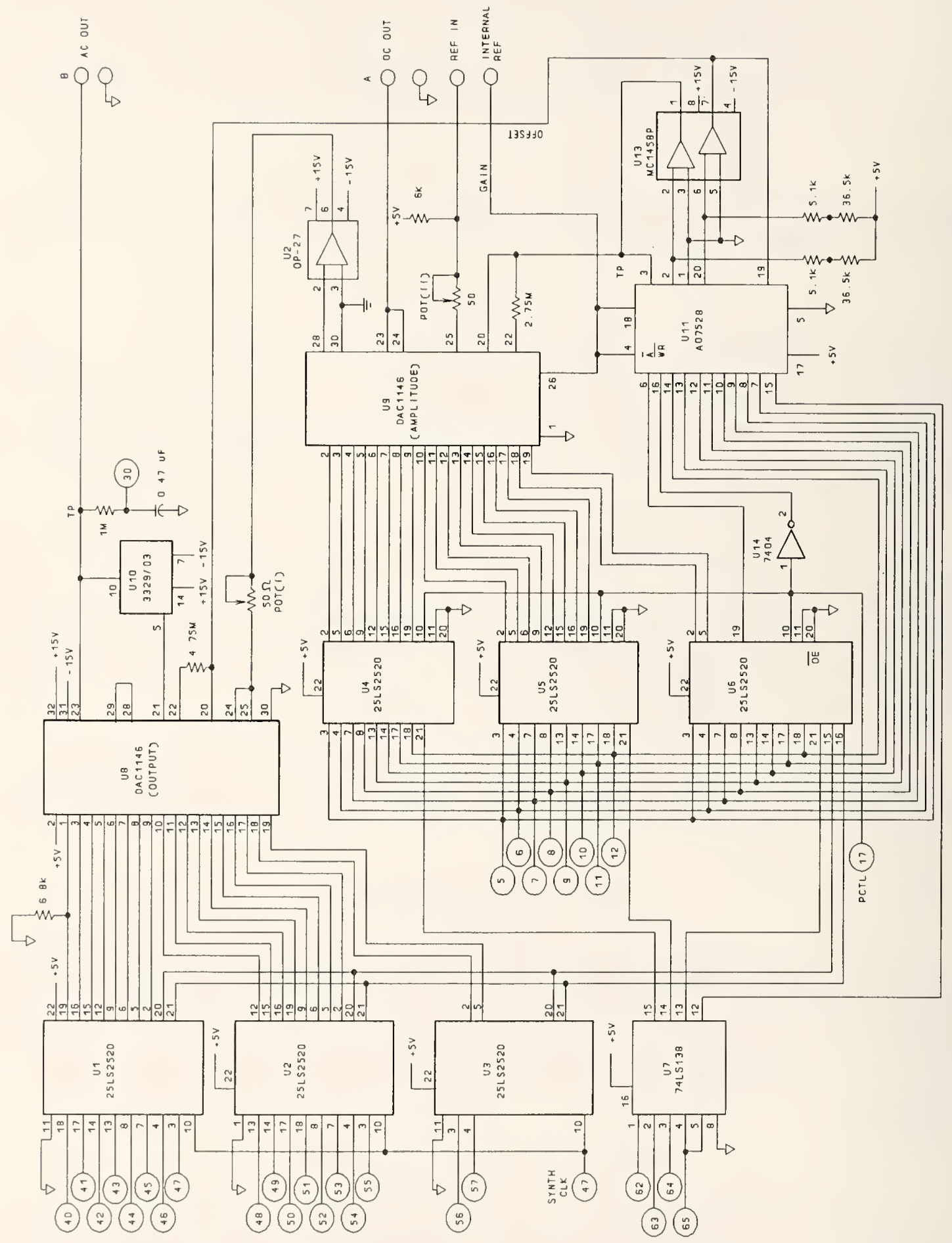

Figure 7. DAC board. 

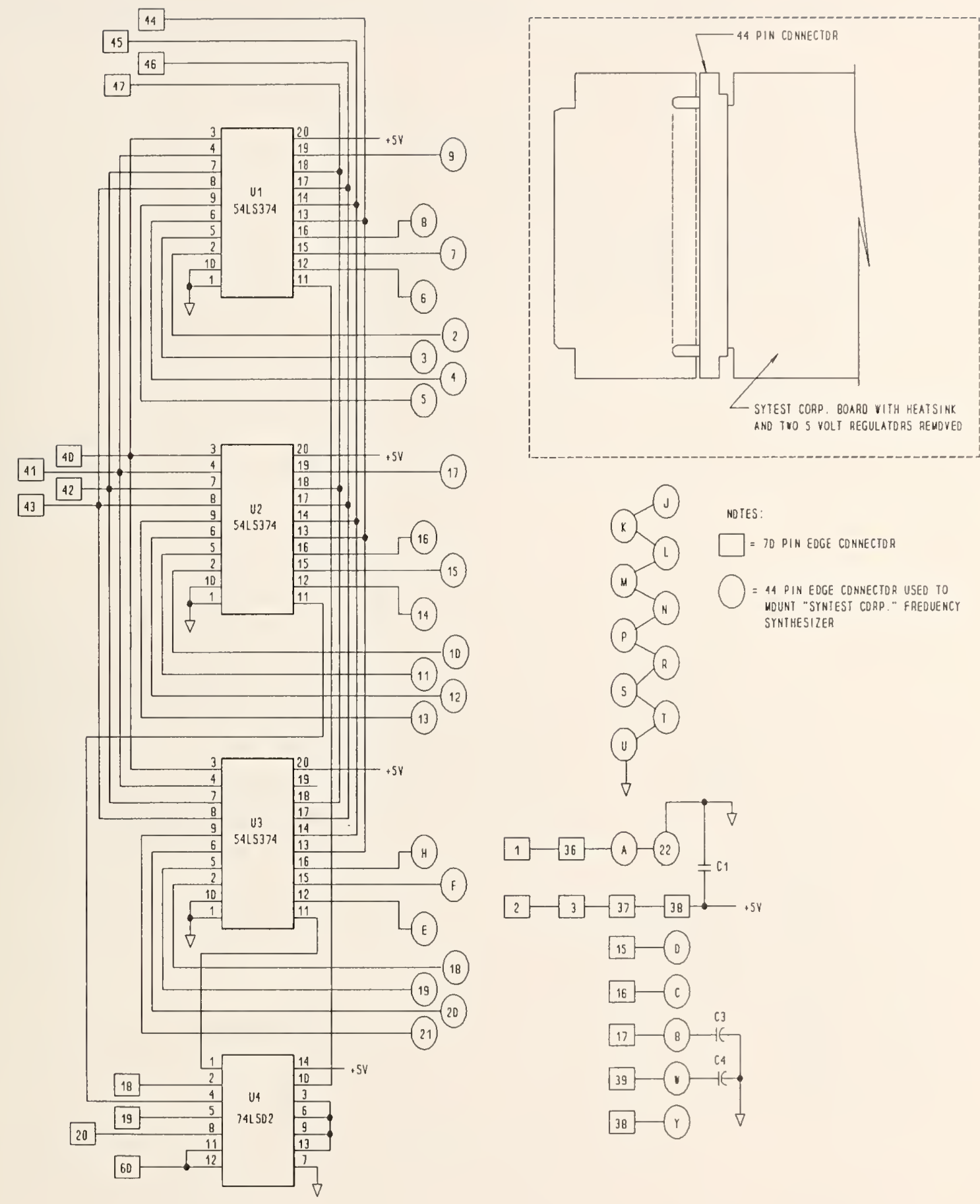

Figure 8. Frequency synthesizer board. 


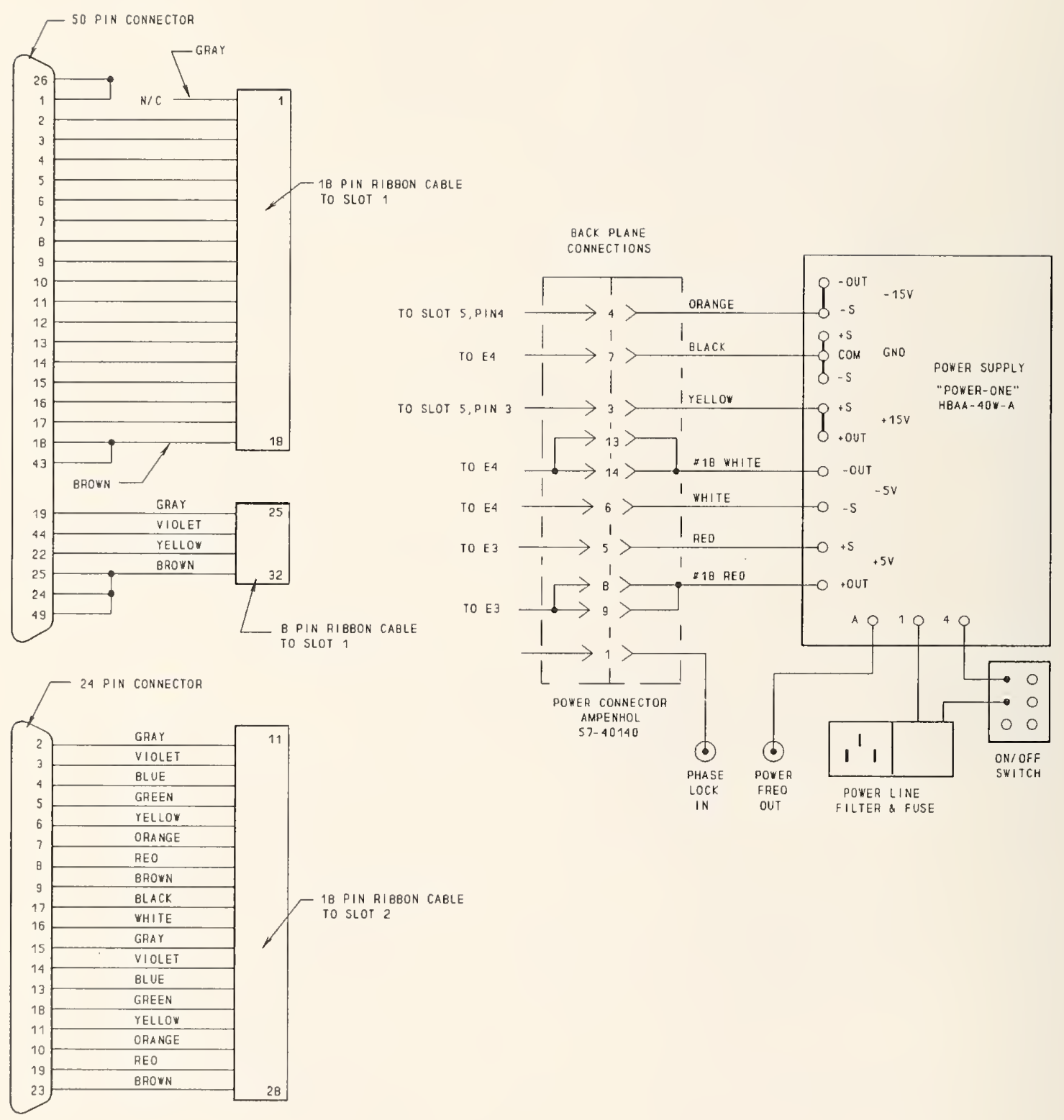

Figure 9. Rear panel GPIO connections and power supply connector. 


\subsubsection{Board Location and Back Plane}

The generator consists of six boards, occupying slots $1,2,3,5,7,9$ (see fig. 10) of a commercial card cage made by Cambion. The back plane wiring diagram for this card cage is shown in figure 11.

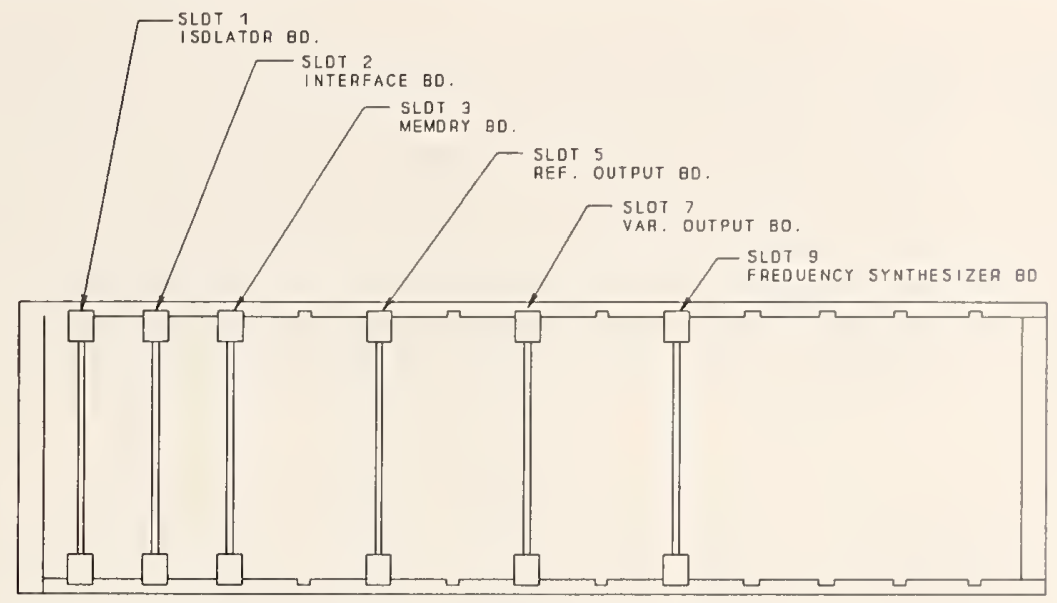

Figure 10. Cambion cardcage slots showing generator board locations.

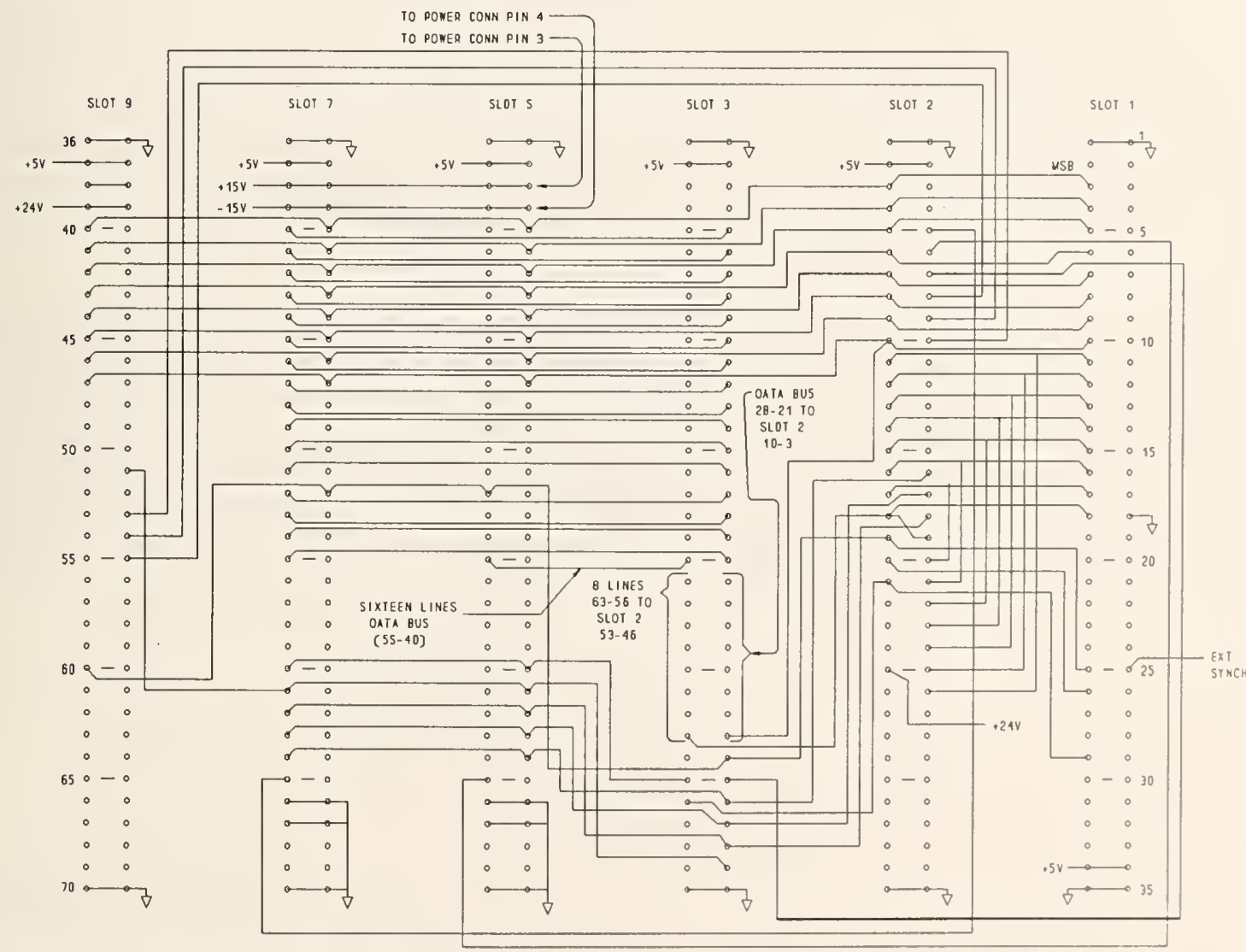

Figure 11. Generator back plane wiring. 


\subsection{Voltage Amplifier}

\subsubsection{Circuit Description}

The voltage amplifer (described in detail in [7]) was primarily designed to boost the output amplitude of the digital generator in order to provide the nominal 120 or $240 \mathrm{rms}$ voltage output of the power calibration source. This amplifier has a fixed gain of 40 and can provide a maximum output voltage swing of 970 volts peak-to-peak or $340 \mathrm{~V} \mathrm{rms}$ at $100 \mathrm{~mA}$ rms. The bandwidth is from dc to $150 \mathrm{kHz}$ and at $60 \mathrm{~Hz}$ the observed no-load, short-term amplitude and phase instabilities are $\pm 5 \mathrm{ppm}$ and \pm 5 microradians, respectively. The amplifier design uses high voltage $\mathrm{N}$-channel MOSFETs in the output driver stage together with a unique circuit topology of opto-isolators between the low-level input stage and the highlevel output stage. In addition, the amplifier was designed to supply up to $100 \mathrm{~mA} \mathrm{rms}$ to accommodate the burden requirements of electrodynamic type meters without causing significant error. A prime goal was to maintain the excellent short-term amplitude and phase stability inherent in the digital generator.

Figure 12a shows the circuit diagram of the voltage amplifier. Each polarity output driver uses a pair of $1000 \mathrm{~V}, \mathrm{~N}$-channel MOSFETs to provide a $2000 \mathrm{~V}$ capability to each polarity driver. The stacked pair of MOSFET drivers provides an operating voltage safety factor of two for each device when operating at maximum peak-to-peak output signal swing. In addition, the total power dissipation for each driver pair is equally divided between two devices. A small trimmer capacitor $\mathrm{C} 23$, helps to balance the differential capacitance across the opto-isolator pair U3 so that the high frequency response for the positive and negative output signal can be better matched. Diodes CR3 \& CR4 separate the signal at the output of U2 and steer the respective polarities to each driver. U2 is a high gain wideband operational type amplifier that provides the major portion of the open-loop gain for the voltage amplifier. U2's input offset errors are reduced by the gain of $U 1$, which in effect servos out any offset errors at the summing junction. In order for this scheme to be effective, U1 must be a precision low-offset type of amplifier. A local compensating network $(\mathrm{C} 1, \mathrm{R} 7)$ around $\mathrm{U} 2$ is necessary in order to shape the gain-bandwidth response to avoid loop oscillation. The diodes at the summing junction protect the amplifiers U1 \& U2 against high voltages during turn-on and output voltage slew-rate limiting.

Figure 12b shows the voltage amplifier's monitoring, control, and overload protection circuitry. U4 converts the amplifier's ac output to a dc value corresponding to the output rms amplitude, while the low pass network (R20, R21, C11, C12) and diodes CR1, CR2 enable relatively small dc output offsets to be monitored in the presence of large ac output signals. Switch SW2 selects which of these signals is to be displayed by the front panel meter. Power to the output stage is controlled by relay K3, K2, and K1, switch SW1, and the state of flip-flop U1. U3 serves as a bipolar peak detector that toggles U1 when a preset output current is reached, which in turn removes the power to the output drivers. The output stage will remain shut down until U1 is reset by Switch SW1. 


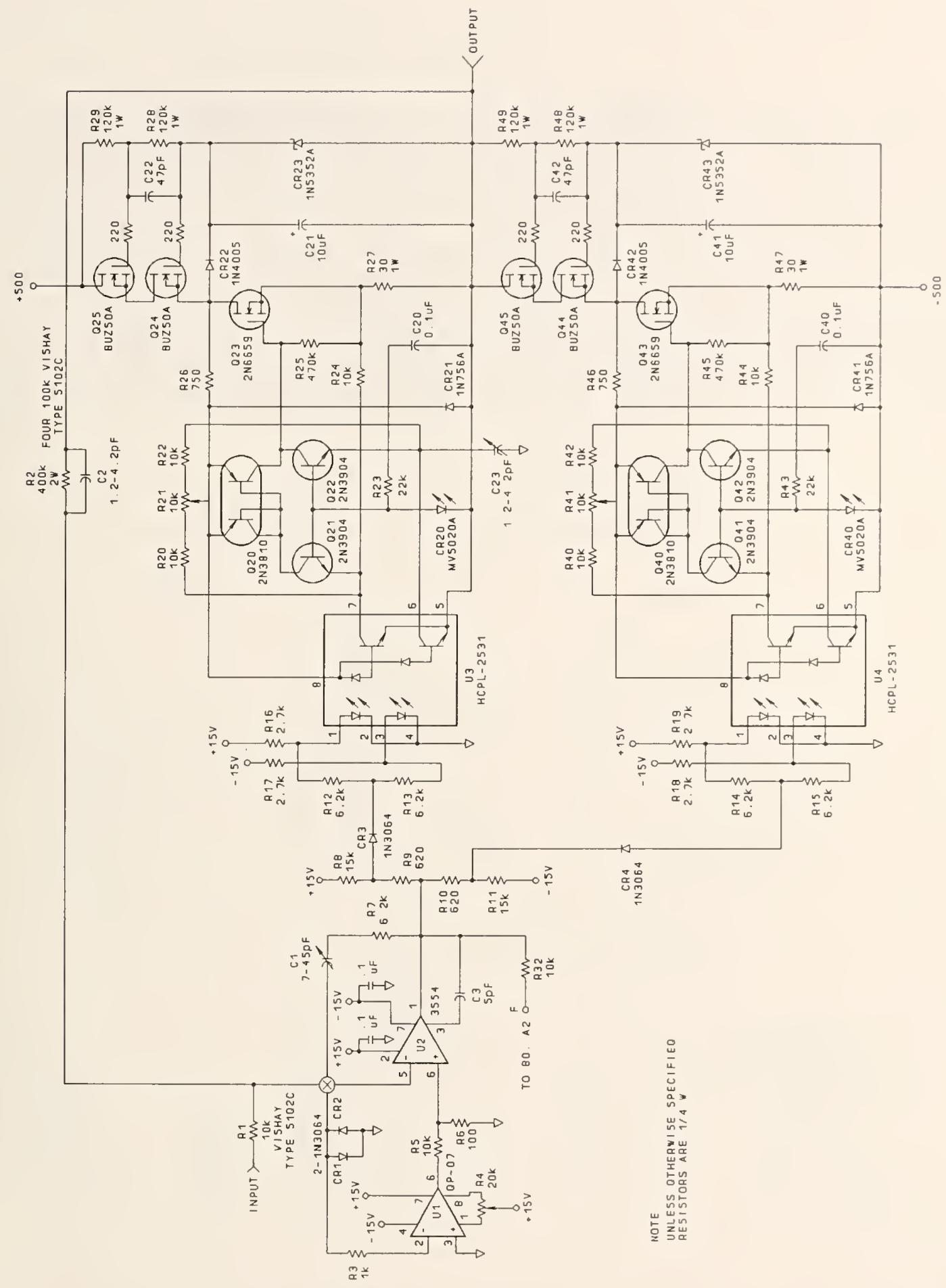

Figure 12a. Complete circuit diagram of precision voltage amplifier: Amplifier circuit. 


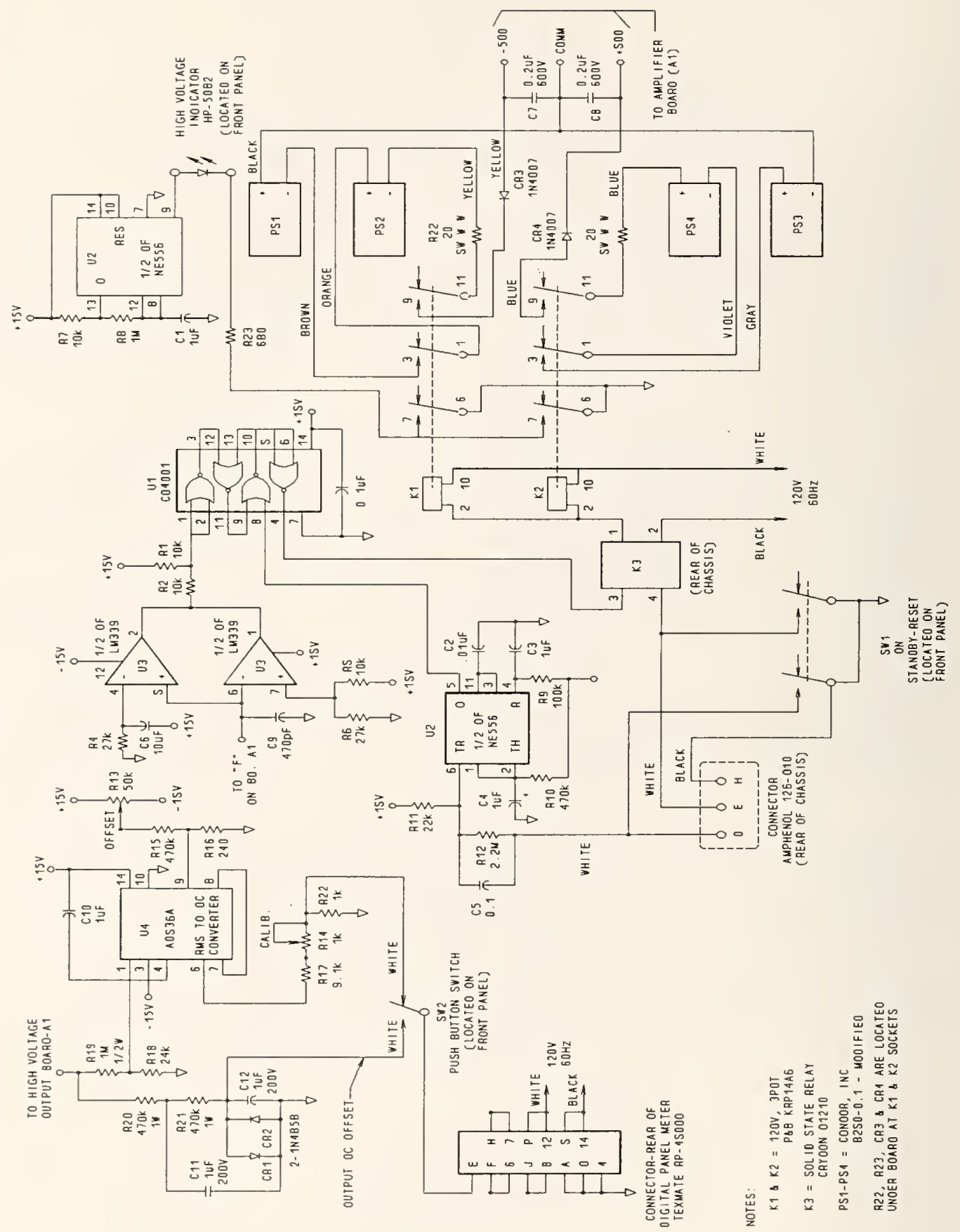

Figure 12b. Complete circuit diagram of the precision voltage amplifier: Control and overload protection circuitry. 


\subsection{Transconductance Amplifier}

\subsubsection{Circuit Description}

A complete circuit diagram of the transconductance amplifier (described in detail in [8]) is shown in figure 13. The operation of the circuit can be described as follows: A voltage applied to the main input at $\mathrm{F}$, produces a current into a load connected across the output terminals. The load current causes a voltage drop across R20 which is amplified by a factor of 10 by a differential amplifier circuit composed of U5 and resistors R16 through R19. The output of voltage the differential amplifier is fed back via R21, where it is compared with the input voltage at the summing junction of U2. Thus, the output current is made proportional to the input voltage. Within the output compliance voltage range, the transconductance amplifier will maintain the same output current for a fixed input voltage regardless of any load change. Since the differential amplifier circuit that senses the voltage across R20 is part of the feedback loop, its phase lag creates a potential source of instability for which compensation must be added. Compensation is provided by modifying the loop-gain response to have a single dominant pole by means of a capacitor C7 across R21.

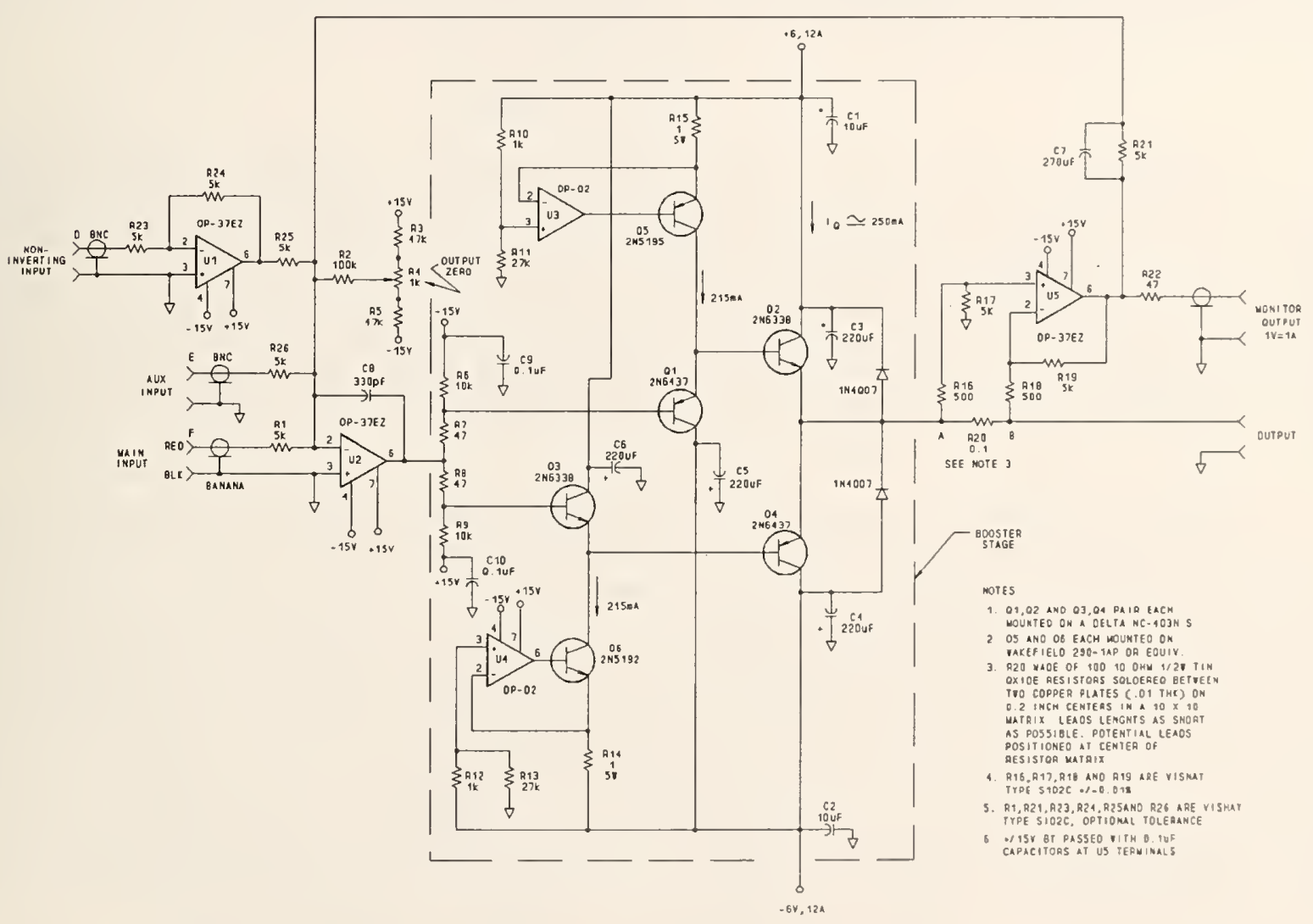

Figure 13. Complete circuit diagram of the transconductance amplifier. 
The output power booster stage, consisting of $\mathrm{Q} 1$ through $\mathrm{Q} 4$, is a class $\mathrm{AB}$ complementarysymmetry emitter follower designed to provide an output current of approximately 15 amperes. Amplifiers $\mathrm{U} 3$, U4, and transistors Q5, Q6 provide complementary fixed current sources for the output booster stage. The output stage is designed to have a quiescent operating current of about $250 \mathrm{~mA}$, which keeps crossover distortion to an acceptable level. Practical considerations for achieving stable operation require proper highfrequency power supply bypassing with both electrolytic and ceramic capacitors at each collector of the booster stage. Also, careful attention must be given to circuit grounding and load ground returns.

\subsection{Switch Box}

The main purpose of the switch box is to facilitate the automation of watt/watthour meter calibration and system test procedures. The switch box is also used for source monitoring. A complete schematic of the switch box circuitry is given in figure 14. The switch box contains switching and control circuitry which enables up to 6 meters under test, MUT1-MUT5 and a non-standard MUT, to be calibrated conveniently. For each of the first 5 meters, MUT1-MUT5, there are two switch box inputs provided, one for the MUT's analog current output and one for the MUT's pulse output, which is assumed to be configured as a standard TTL, open-collector. The non-standard MUT is provided with only one analog voltage input. The relays in the box are remotely programmed over a portion of the HP GPIO bus that has been channeled through the digital generator. These bus output pins are located on card cage slot 2 pins 11-28 and exit the digital generator via a rear panel IEEE-488 type connector (see fig. 9).

\subsubsection{Circuit Description/Programming}

The triangular, numbered tabs in figure 14 represent wiring traces present on the actual circuit board of the switch box. The traces were represented this way for the sake of schematic clarity. Connections to and from the switch box, measuring devices, and MUTs are made at the circles labeled "R" and "B", for "red" and "black" banana plugs, as well as at other connectors labeled in the figure. The analog outputs of each standard wattmeter are connected to the switch box inputs as shown in figure 14 . For energy measurements, each MUT's open-collector pulse output is first "pulled up" to $+5 \mathrm{~V}$ before being channeled through multiplexer U6 to the switch box's counter output. The frequency of the pulse output may be measured by any frequency counter capable of being connected to the controller via an IEEE-488 bus.

For power measurements, the circuit includes an array of both latching and non-latching relays. The relays are switched using either line drivers, (U1,U4), or latches, (U2,U3). The non-latching relays (S1S10) are switched using the buffered outputs of latches U1 and U4. These relays are used to switch the current output of a selected MUT from a low-precision $1-\mathrm{k} \Omega$ resistor to the standard $1-\mathrm{k} \Omega$ resistor used in an actual power measurement. The latching relays (R1-R6) require only a brief pulse from line drivers U2 and U3. This pulse is provided by programming U5, a 3-8 line decoder, to toggle output pin \# 15 low by toggling pins 4,5 with the generator's CTL0 signal (control bus enable). These latching relays (R1-R6) channel the voltage outputs of various devices to the system DVM input. These voltages include the generator's dc-offsets, the output of the non-standard MUT, the Guildline 1300A Transfer Standard's output (used in the Power Bridge [10]), the transconductance amplifier's monitor output, and the voltage amplifier's output. With the ability to automatically sample these signals using the system DVM and counter, power and energy measurements can be made simultaneously in intervals of ten seconds per MUT.

The generator's control/data bus is also used for programming the switch box (for programming

codes, see sec. 3.5.4, table 2). The programming steps are similar to those required to program the generator's internal boards. These steps are performed in the subprogram, Switch, as described in section 3.4.4. 


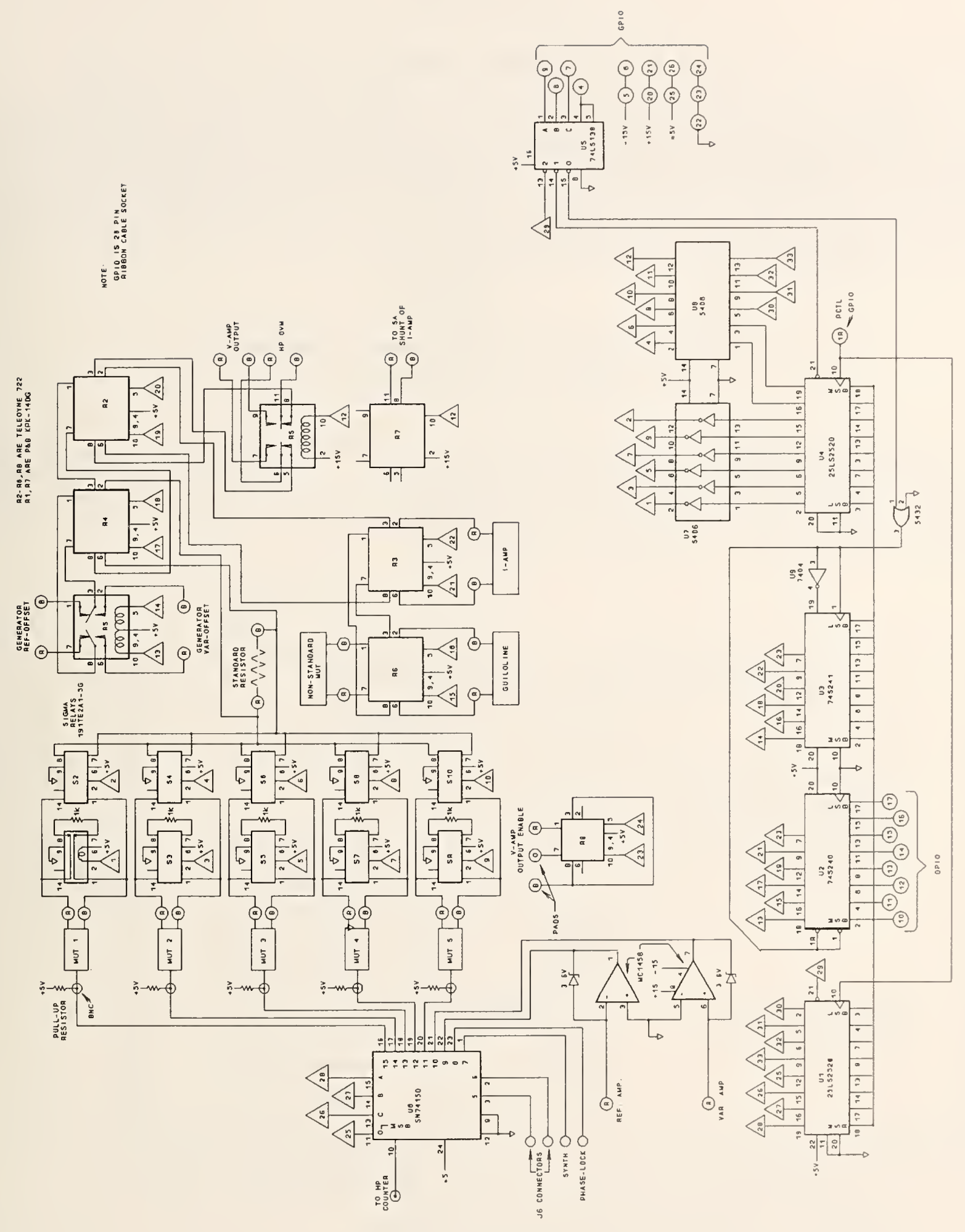

Figure 14. Complete circuit diagram of the switch box. 


\section{SOFTWARE}

\subsection{The MET_6 Program}

There are three basic functions performed by the MET_6 software. First, to control the digital generator, second, to characterize and correct generator errors so that they fall within certain bounds, and third, to semi-automate wattmeter testing procedures. The latter tasks are performed by a group of routines that are very system dependent and may be omitted with only minor changes to the basic software. The MET_6 program was written initially in HP BASIC version 2.1 for use on an HP 9836C desktop computer. With the required binary drivers, the program will also run on HP BASIC 3.0 and 5.0 on HP series 200 and series 300 machines (equipped with the series 200 keyboard).

\subsection{Software Considerations Based on System Configuration}

\subsubsection{Switch Box vs. no Switch Box}

There are several MET_6 variables that must be properly defined, depending on whether the power/energy calibration system includes a switch box (as described in sec. 2.4) or not. Certain subprograms use these variables to determine the proper measurement algorithm to follow (see sec. 3.4). Table 1 below lists these variables and their values based on system configuration. For a complete explanation of all variables used in the MET_6 program, see APPENDIX A.

\begin{tabular}{|c|c|c|c|}
\hline Configuration & $\underline{\text { Variable }}$ & Line \# & Value \\
\hline $\begin{array}{l}\text { No switch box, } 4 \text { counters, } \\
1 \text { HP } 3457 \text { A DVM with } \\
\text { Multiplexed input channels. }\end{array}$ & $\begin{array}{l}\text { No_switch_box } \\
\text { Col_max } \\
@ \text { Dvm } \\
\text { @Cntr1 } \\
@ \text { Cntr2 } \\
@ \text { Cntr3 } \\
@ \text { Cntr4 } \\
\text { No_switch_box } \\
\text { Col_max } \\
@ \text { Dvm } \\
@ \text { Cntr1 }\end{array}$ & $\begin{array}{l}595 \\
425 \\
330 \\
\\
335 \\
340 \\
345 \\
350 \\
595 \\
425 \\
330 \\
335\end{array}$ & $\begin{array}{l}1 \\
4 \text { or6 } \\
\text { Any unique HPIB } \\
\text { interface select } \\
\text { code (ISC) } \\
\text { unique HPIB ISC } \\
\text { unique HPIB ISC } \\
\text { unique HPIB ISC } \\
\text { unique HPIB ISC } \\
0 \\
4 \text { or } 6 \\
\text { unique HPIB ISC } \\
\text { unique HPIB ISC }\end{array}$ \\
\hline
\end{tabular}

To set the variables listed above in table 1, the procedure is as follows:

1. "PAUSE" the program and "EDIT" the line \# given;

2. Change the value in the indicated line and "ENTER" it;

3. "RE-STORE" the program (or, "PURGE" and "STORE"). 


\subsection{Generator Control Routines}

Figure 15 outlines the relationships between the various routines and is intended to show only their basic interactions, not the detailed program execution flow. These routines may be separated into two groups consistent with their relative utility. The first to be discussed, the interactive I/O group, share a common symmetry of operation that allows them to be easily understood and maintained. These are the Adj_phase, Synth_load, Amplitude, and Cor_dac subprograms. The rest of the subprograms may be loosely grouped together, based on the fact that they perform specialized tasks that require little or no interaction with the user.

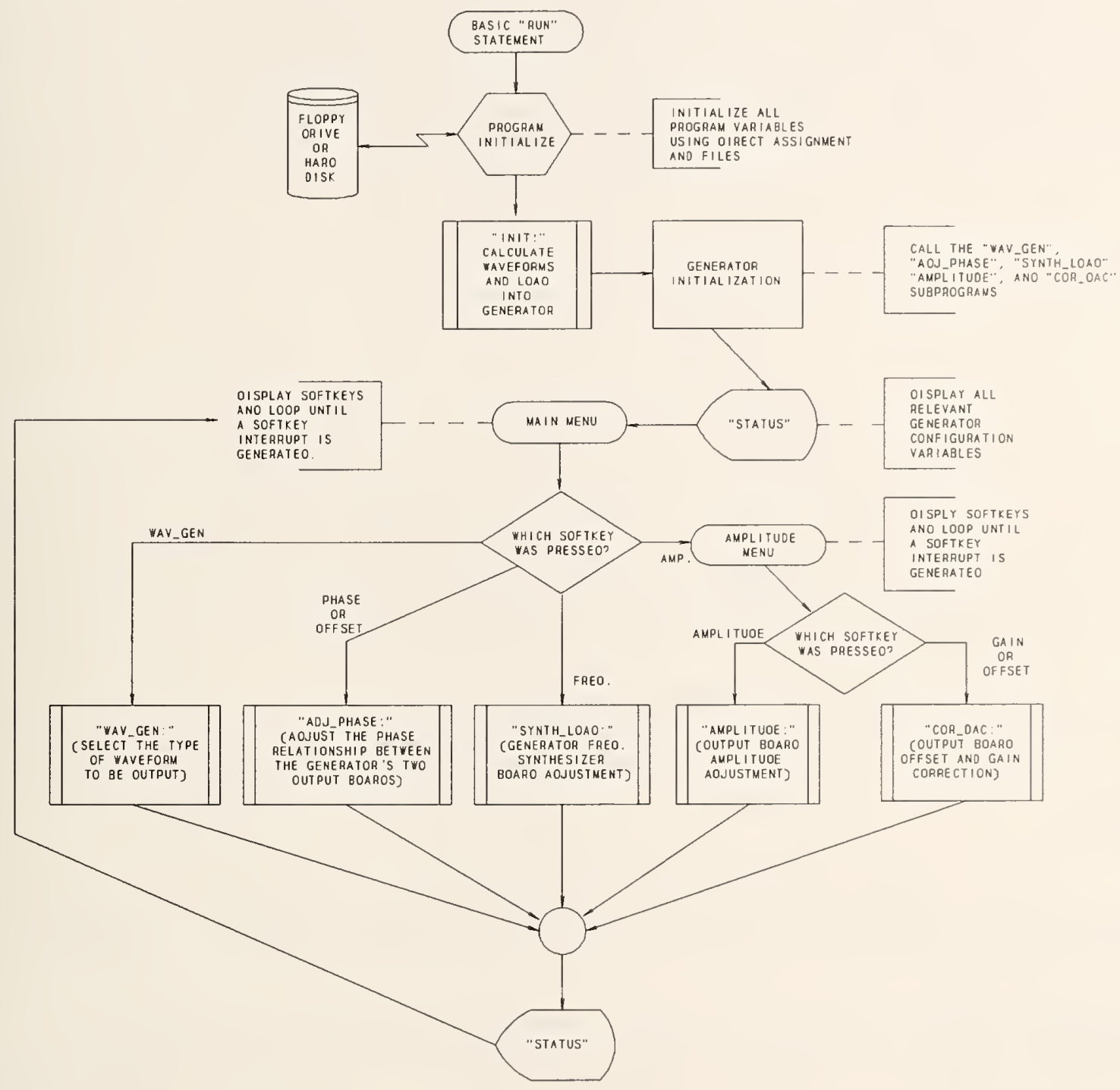

Figure 15. Basic relationships of various routines in the MET_6 program.

In the discussion below, the term 'function key' refers to the ten rectangular keys labelled $\mathrm{k} 0$ through $\mathrm{k} 9$ found on all HP series 200 desktop computers. Two lines at the bottom of the computer's screen indicate the alphanumeric labels assigned to each k0-k9 key. For clarity, the labels that appear on 
the computer screen during the MET_6 program execution are enclosed in quotes in the discussion below. Also, numbers, shown in brackets refer to the length of a string, not to the references at the end of this report.

\subsubsection{Interactive I/O Routines}

\subsubsection{Amplitude}

To enter this routine, press the "AMP." function key when in the main menu. Three additional choices will appear - "REF_WAVE", "VAR_WAVE", or "EXIT". The first two choices are for reference waveform and variable waveform amplitude control, respectively, while the third will cause an exit to the main menu. Pushing the "REF_WAVE" function key will cause four additional keys to appear - "AMP", "GAIN", "OFFSET", AND "LINEAR". In order to enter the Amplitude subroutine, press the "AMP" function key. Once inside the subroutine, there are three ways in which the user may alter the amplitude value: 1) pressing the \pm 100 to \pm 1 least significant bit (LSB) function keys, 2) turning the keyboard knob, or 3 ) directly entering the desired value. The three columns located on the lower portion of the screen indicate the amplitude, change from the initial value in LSB's, and the apparent and actual amplitude DAC settings, respectively. On the screen, the binary string under the "APPARENT" heading is the DAC amplitude setting corresponding to the amplitude value on the lower left of the screen, while the binary string under the "ACTUAL" heading includes any gain corrections that may be present.

Gain, dc offset, and amplitude linearity corrections are handled by the routine Cor_dac (see sec. 3.3.1.3 below). Since the amplitude values Ref_amp and Var_amp are used within the software in many calculations, including gain corrections, the Amplitude routine should only be used to set up the ideal (desired) amplitude. The Amplitude routine automatically calls Cor_dac after every amplitude change, resulting in a constantly updated dc offset voltage correction corresponding to a linear correction curve. In addition, Amplitude routine computes a new gain correction according to a similar correction curve set up in Cor_dac. After a call to Amplitude routine, the internal variables Ppm and Voltage (see app. A) are corrected to values allowable by the 18-bit amplitude DAC (U9 on the output board). A discussion of how to characterize the generator and construct these curves is given in section 5 .

Due to software gain DAC corrections, which are transparent to the user, the Amplitude routine behaves rather unpredictably when incrementing the amplitude DAC near full scale, which is the amplitude where the voltage amplifier is automatically enabled. The DAC settings on the lower right of the screen were included mainly as a way of keeping track of exactly what is happening during this discontinuity of operation.

If, when the keyboard knob is used to increment the gain or amplitude, a value is selected that exceeds the maximum output DAC binary setting, the user will be alerted to this fact and the output DAC set to its maximum value.

Finally, provisions are made in the Amplitude routine to remotely enable or disable the voltage amplifier with the $(\mathrm{k} 0)$ function key. Enabling or disabling is accomplished by entering the Amplitude routine via the "REF_AMP" key and then using the "ENABLE" (k0) function key. The amplifier is automatically enabled when the operator enters a reference voltage above $7.071 \mathrm{~V}$ (full scale of amplitude DAC for sinewave functions).

\subsubsection{Adj_phase}

To enter this routine from the main menu, use either the "PHASE" or "OFFSET" function key. To set up a direct reading phase difference between the reference and variable waveform channels, first use 
the "OFFSET" key to adjust the inherent channel phase error to zero and then use the "PHASE" key to set the desired phase difference. The phase difference between the two channels is computed as the difference between the global variables Phaz and Offst. For example, the effective phase difference between the two waveforms resulting from a Phaz of 30 degrees and an Offst of 1 degree is 29 degrees.

The behavior of the I/O subroutines in Adj_phase is similar to that of Amplitude, Cor_dac, and Synth_load. The main difference between Adj_phase and the others is that the actual output of the new waveform values and address difference is done in another subprogram, Change_phase, which is described in section 3.3.2.

Adj_phase has two modes of operation, fine and coarse. In the coarse mode, only the RAM address difference is changed, resulting in a phase resolution of $1 / 2048$. In the fine mode, although the algorithm used to compute the values in RAM allows for an extremely fine resolution, a reasonable value for the highest resolution was chosen to be $1 \mu \mathrm{rad}$. When changing the phase at intervals lower than $1 / 2048$, Adj_phase calls Change_phase with Sel_ect $=2(1=$ coarse, $2=$ fine $)$ and also passes the real arrays Real_var and Var_diff to Change_phase, where it recalculates the integer buffer values and outputs them to RAM.

\subsubsection{Cor_dac}

This subprogram may be accessed from the main menu by pressing the "AMP." function key, choosing either "REF_AMP" or "VAR_AMP," and then deciding whether Cor_dac is to process "GAIN," "OFFSET," or "LINEARITY." In each of the three cases, the operation of Cor_dac is as follows:

(a) "GAIN" key (k3 or k8): The functionality of the routine is similar to that of the Amplitude subprogram (see discussion above in sec. 3.3.1.1). The values across the lower portion of the screen represent the gain correction in volts presently being applied to the Ref_amp or Var_amp variables, the change (in ppm of reading) between the desired voltage (Ref_amp or Var_amp) and the corrected voltage, and the "APPARENT/ACTUAL" DAC settings, respectively. The routine uses the input parameters Slope, Intercept, and Voltage to calculate Ppm and then calls Amplitude (see fig. 15) to load the new corrected amplitude DAC word into the appropriate generator output board. An additional function performed by the call to the Amplitude routine is to return to Cor_dac a corrected value of Ppm, since only discrete values are permitted by the 18-bit DAC. In the gain mode, Cor_dac does not directly manipulate Ppm. Instead, Slope is altered and Ppm recalculated.

(b) "OFFSET" key (k4 or k9): Operation is similar to "GAIN" above. Cor_dac controls the amplitude DAC's offset voltage by altering the setting of the 8-bit MDAC (U11 on the output board). To do this, Cor_dac must be called with the input parameter, Dac_choice, set to 1 . In the offset mode, Cor_dac uses the input parameters Slope, Voltage, and Intercept to calculate an 8-bit value, Vo_lts, that is then loaded into U11 of the appropriate output board. In this mode, Cor_dac does not manipulate Vo_lts directly. Instead, it increments or decrements Intercept. This seems to be the best method because the characteristic slope of the dc offset correction curve seems to stay relatively constant over time. The values displayed across the lower portion of the screen are from left to right the applied DAC setting in volts and the change (in LSB's) between the present 8-bit DAC setting and the initial setting (shown at the top of the screen).

(c) "LINEARITY" key (k2 or k7): In this mode, Cor_dac controls the A-channel of the 8-bit dual MDAC (U11) on the appropriate output board. The behavior of Cor_dac in this mode is sinilar to that discussed in the above "OFFSET" mode with the exception that Cor_dac manipulates Voltage directly with no reference to either of the input parameters Slope or Intercept. The purpose of this routine is to ensure that the amplitude errors are constant (the same ppm of reading) throughout the voltage range. 
A discussion of how this is accomplished is given in the section on generator characterization. Once this value is determined, it should not be changed until the next output board adjustment, or else serious amplitude non-linearity may result.

\subsubsection{Synth_load}

This is the controller subprogram for the generator's frequency synthesizer board. To enter this routine from the main menu, simply press the "FREQ." function key $(\mathrm{k} 7)$. The methods of data input are identical to the Amplitude, Adj_phase, and Cor_dac routines, which are direct entry, knob turning, or choosing a defined function key.

Because of the synthesizer's design, the actual value of an LSB in $\mathrm{Hz}$ is highly dependent on which frequency range the synthesizer board is presently set on. In the event of a frequency change, the Synth_load routine determines both the proper range and frequency resolution of the synthesizer board's output, the latter of which may range from as fine as $10 \mu \mathrm{Hz}$ to as coarse as $100 \mathrm{~Hz}$.

The internal structure of the subprogram is very straightforward. Since there are no frequency corrections, the Synth_load routine basically performs only two tasks: 1) to handle user I/O, and 2) to update F, the variable containing the current frequency synthesizer setting. The Synth_load routine contains only one input parameter, Freq, that is usually passed by value. The seemingly redundant presence of both $F$ and Freq stems from the fact that Freq does not always indicate the true synthesizer setting. For instance, when Freq $=10,000(10.000 \mathrm{kHz}), \mathrm{F}=10.000$ and $\mathrm{F}$ _unit $\$=$ "kHz." Calling Synth_load with Freq $=0$, an illegal value for the synthesizer board (see data sheet), causes the subprogram to initialize its I/O handling subroutines, Format and Softkey. Thus, Synth_load may be used to simply set up a synth board setting or to also interact with the user.

\subsubsection{Subprograms to Perform Specific Generator Control Tasks}

\subsubsection{Change_phase}

This is a subprogram invoked by Adj_phase that performs the actual generator channel phase changes. Depending on the value of Sel_ect, Change_phase will either calculate the address offset between the two channels and call Cnt_vals to output this value to the memory board (Sel_ect=1) or Change_phase will use matrix operations to calculate new variable channel RAM values and then call Out_put to load the new values and set the address offset $(\mathrm{Sel}$ ect $=2)$. This process can be more clearly understood by examining fig. 15 .

\subsubsection{Cnt_vals}

This subprogram is transparent to the user and is responsible for loading the memory board's RAM address counter with the desired increment in order to create a phase difference between the two channels. The desired increment is passed (usually by value) to Cnt vals via the input parameter, Address add. The variables L2_mss and L2_lss, which correspond to latch $\bar{U} 2$ on the memory board, are updated during each call to Cnt_vals.

\subsubsection{Init}

This subprogram initializes the appropriate channel's Real and Diff arrays as well as the integer buffer used to output the values to RAM. Depending on the parameter Function\$, Init will calculate 2048 sin, ramp, triangle, square, zeroes, ones, minus ones, or arbitrary function values, load the values into the Real, Diff, and BUFFER data structures, output the BUFFER to the appropriate memory(s), and finally, reset the correct amplitude values on the output boards. 


\subsubsection{Out_put}

This is a subprogram responsible for loading the appropriate memory channel(s) with the contents of the INTEGER buffer passed to it. Out_put also takes care of restoring the proper counter increment (RAM address offset) by calling Cnt_vals.

\subsubsection{Process_key}

This is a subprogram designed to eliminate the use of the Basic "INPUT" command, which halts program execution and disables the function key interrupt routines when waiting for an "ENTER" command. Process_key acts upon a keyboard interrupt and checks the keyboard buffer. The subprogram then interprets the data as either legal or not, depending on the Message input parameter. Upon the occurrence of an "ENTER" key, Process_key then either returns the accumulated data in Value (numeric input only) or shifts it into Value\$ (alpha-numeric data). Process_key may also update Message according to the data passed to it (see the code documentation).

\subsubsection{Set_inc}

This subprogram sets up the memory address counter according to the variable Inc, the number of steps per period. The desired increment is stored in another variable, Inc_rement, because Inc must be set to zero during certain memory board operations.

\subsubsection{Status}

This subprogram is usually called after the completion of an interactive I/O subprogram. Status displays the following parameters: Fr_eq, F*Inc, Inc, Rivd, Civd, Offst, Phaz, Ref_amp, Var_amp, R_func\$, and V_func\$.

\subsubsection{Step_num}

This is a subroutine that allows for the manipulation of the number of steps per period of the output waveform. The default value of 2048 may be decreased in binary steps down to a minimum of 2 steps per period by using either the defined function keys or by direct entry. The basic steps taken to accomplish this are: 1) call Set_inc to set the proper memory board counter increment 2) call Synth_load to set the new sampling rate $\overline{3}$ ) recalculate the $\mathrm{rms}$ value of the waveform, and 4) restore the proper phase value by calling Change_phase.

\subsubsection{Wav_gen}

This subroutine handles the I/O tasks for the subprogram Init (see 3.3.2.3 above). The type of waveform to be loaded in memory as well as the desired channel, may be chosen by using the defined function keys.

In order to load a specific arbitrary waveform, the program must first be "PAUSE"d and line 4100 of Init modified. To preserve this function as the arbitrary waveform the program containing this updated line 4100 must be "RE-STORE"d.

\subsubsection{Machine_state}

This subprogram may be accessed from the main menu by using the "MORE" (k0) key and then the "GEN VALS" (k4) key. 
The purpose of this routine is to allow the user to either store or retrieve all major generator variables from disk storage. These groups of variables (generator states) are contained in the files "Gen_state," the file reserved for temporary state storage, and "Met6vals," the file reserved for permanent (default) state storage, resident on the MET_6 program disk.

Once inside the Machine_state subprogram via the "GEN_VALS" key, the three resulting choices are "EXIT" $(\mathrm{k} 0)$, "DEFAULT" $(\mathrm{k} \overline{4})$, and "TEMP" $(\mathrm{k} 9)$. "DEFAULT" is used to retrieve/store values from "Met6vals" while "TEMP" operates on "Gen_state." To store the present state as the default state, use the "DEFAULT" and then "STORE" function keys. To retrieve the generator's default state from disk, use the "DEFAULT" and "RETRIEVE" keys. The same procedure applies when using the "TEMP" function key.

The "GEN VALS" key may also be used to save calibration system configurations for several different test points by setting up the system at the desired point, inserting a disk dedicated for power/energy calibrations at this test point and "STORE"-ing the system state in the "TEMP"-orary state file. In this way, system setup data as well as error data for specific test points may be collected on separate disks (see sec. 3.4.1 below for information concerning calibration error data storage).

\subsection{Generator Characterization Subprograms}

The subprograms in this section are ones which aid in characterizing the digital generator. Once the correction factors are determined, these routines may also be used to fine tune the corrections or to adjust the correction for a different operating point. The discussion presented here deals mainly with how the routines function and with gaining an understanding of how to use them. Section 5. discusses in detail how an actual characterization of the generator is carried out using these routines.

\subsubsection{Calibrate}

This routine employs a rotating menu system that gathers relevant input parameters for use in the subprogram, Measure. To enter this subprogram from the main menu, press the "MORE" (k0) and then the "CALIBRATE" (k5) function keys. From this point, there should be three function key options, "SELECT>OPTION," "SECOND PAGE" or "EXIT." In addition, the user may move around the menu by using the keyboard knob.

The menu used in Calibrate contains two levels. The first page, or primary menu, contains the choices between which generator characteristics are to be measured. Pressing the "SECOND PAGE" function key (k9) will result in the relevant Measure input parameters to be displayed in a similar (secondary) menu. These parameters relate to the row at which the arrow was pointing prior to entering the secondary menu by pressing the "SECOND PAGE" function key. In order to verify this, the top line of the screen in the secondary menu should be the same as the selected row in the primary menu. To return to the primary menu, press the "FIRST PAGE" key (k9) that has replaced the "SECOND PAGE" key.

The various input parameters for both the Calibrate and Measure subprograms are stored in string, integer, and real array structures, which are named Calib_val\$(12,4)[30], Cal_int_vals(10,5), and Cal_r_vals $(10,6)$, respectively. These values are stored in the ASCII file "CAL_VALS" during program initialization. The "CAL_VALS" file may be created by running the program Calval_config in the PROG filc "C_VAL_CON."

It is sometimes necessary to alter the values stored in the above data structures. To do this, the user must be in the secondary menu. Once therc, the keyboard knob is used to point to the desired parameter, which will be highlighted in blue, if the monitor is color, or white, if the monitor is 
monochromatic. The new value may then be "ENTER"ed through the keyboard. If the value is a valid one,it should appear in the red (color monitor) or white (monochrome monitor) field after hitting the "ENTER" key.

The measurement cycle must be started in the primary menu, so to get there, use the "FIRST PAGE" key and then the "SELECT>OPTION" (k0) key. At this point Calibrate will turn control over to the Measure subprogram. If a data disk with the proper filename is not present in drive ":INTERNAL," the subprogram Measure will pause and wait for either the file to be created or the disk to be put in the drive. To find out the filename, press "filename $\$$ " and "EXECUTE." If at any time a filename other than the default name is desired, a different one may be set by performing the following steps:

1. Leave the ":INTERNAL" drive empty before using the "SELECT>OPTION" key.

2. Wait for Measure to pause.

3. "EXECUTE" a command like "Filename $\$=x x x . "$

4. Reinsert the disk with the filename on it.

5. "CONTINUE" the program.

\subsubsection{Compliance}

This subprogram is used to add an extra gain term to the variable channel waveform in order to correct for transconductance amplifier gain changes when operating at different output compliance voltages. Compliance first calls Measure to measure the ac compliance voltage across the output of the transconductance amplifier. This value is them used in a linear correction equation involving C_slope and C_intercept to evaluate C_ppm, which is then added (in ppm of reading) to all subsequent variable channel amplitude DAC settings. The procedure for characterizing the generator for compliance related amplitude errors is given in section 5.3.

To enter Compliance from the main menu, press the "AMP.", "VAR_WAVE" and "COMPLIANCE" softkeys in that order. When entering Compliance, there are only two choices, to "EXIT" or to "READ COMPLIANC." Before enabling the " $\pm 10 \mathrm{PPM}^{n}$ or " $\pm 1 \mathrm{PPM}^{n}$ function keys, the current amplifier's compliance voltage must first be read. After that, these keys may be used to increase or decrease the intercept of the compliance correction curve, C_intercept.

To ensure the proper variable channel gain correction is present, Compliance should be used whenever the burden on the transconductance amplifier changes.

\subsubsection{Measure}

Subprogram Measure is used to take automated measurements using either a Hamburger K2004, HP 3456A, HP 3457, or FLUKE 8506A. Measure may be used to take either single data points returned in the input parameter, Value, or it can take groups of data in which some generator parameter (usually amplitude) has been incremented throughout a range specified in the subprogram, Calibrate.

If the variable Row $>0$ upon entry to Measure, the routine uses the contents of Calib_val\$(12,4)[30], Cal_int_vals(10,5), and Cal_r_vals(10,6) assigned in Calibrate (see discussion above) to control its remaining execution path. The various fields of these data structures are assigned in the following way: 


$$
\begin{aligned}
& \text { Calib_valS }(12,4)[30] \text { : } \\
& (\mathrm{x}, 1)=\text { Type of } \quad(1,4)=\text { "Reset_delay" } \quad(7,4)=\text { "Interval" } \\
& \text { Calibration } \\
& (x, 2)=\text { Device } \$ \\
& (2,4)=\text { "Num_of_reps" }(8,4)=\text { "Limit" } \\
& (\mathrm{x}, 3)=\text { Filename } \$ \\
& (3,4)=\text { "Ac_or_dc" } \quad(9,4)=\text { "Percent_of_fs" } \\
& (4,4)=\text { "Gain" } \quad(10,4)=\text { "P_of_fs_limit" } \\
& (5,4)=\text { "Settle_time" } \quad(11,4)=\text { "Enable" } \\
& (6,4)=\text { "Full_scale" } \quad(12,4)=\text { "Device } \$
\end{aligned}
$$

$$
\begin{aligned}
\text { Cal_int_vals(10,5): } \\
(\mathrm{x}, 1)=\text { Reset_delay } \\
(\mathrm{x}, 2)=\text { Num_of_reps } \\
(\mathrm{x}, 3)=\text { Ac_or_dc } \\
(\mathrm{x}, 4)=\text { Gain } \\
(\mathrm{x}, 5)=\text { Settle_time }
\end{aligned}
$$

$$
\begin{aligned}
& \text { Cal_r_vals(10,6): } \\
& \begin{aligned}
(\mathrm{x}, 1) & =\text { Full_scale } \\
(\mathrm{x}, 2) & =\text { Interval } \\
(\mathrm{x}, 3) & =\text { Limit } \\
(\mathrm{x}, 4) & =\text { Percent_of_fs } \\
(\mathrm{x}, 5) & =\text { P_of_fs_limit } \\
(\mathrm{x}, 6) & =\text { Enable }
\end{aligned}
\end{aligned}
$$

In the above list, the expression " $(\mathrm{x}, \mathrm{x})$, " where " $\mathrm{x}$ " stands for any allowable array index or the index given, represents the two-dimensional index for the listed data structures. For an explanation of these variables, see the table of MET_6 variables, APPENDIX A.

When subprogram Measure is called with variable Row $<=0$, the routine takes only a single measurement, returning the value read in Value. The conventions are:

\section{On Entry:}

$$
\begin{array}{ll}
\text { Row }=-1: & \begin{array}{l}
\text { Take one reading without initializing meter } \\
\text { (HP 3456A). }
\end{array} \\
\text { Row }=0: & \begin{array}{l}
\text { Initialize the meter (HP 3456A) to read dc voltage } \\
\text { and take one reading. }
\end{array} \\
\text { Row }=>0: & \begin{array}{l}
\text { Use the data structures Calib_valS, Cal_int_vals, } \\
\text { and Cal_r_vals to control subprogram execution. }
\end{array}
\end{array}
$$

\subsubsection{Offset_zero}

This is a simple, fast subprogram that employs recursion to zero the dc offset of either the reference or variable waveform channel. The code for this routine is very simple, but because it calls Measure, the output of the channel to be zeroed must be connected to the HP 3456A input. IMPORTANT: For the variable channel waveform, the inverting output monitor of the transconductance amplifier must be used or Offset_zero won't behave properly. This routine is called by Measure when Row $=3$ or Row $=6$ ("V(I)-AMP OFFSET LINEARITY") in the Calibrate subprogram.

Offset_zero may also be reached from the main menu by pressing the "AMP.", "REF_AMP" or "VAR_AMP", "OFFSET" and "ZERO DC OFFSET" function keys in that order.

\subsection{Subprograms useful for Power/Energy Calibrations}

The subprograms discussed here were developed primarily for the calibration of power related instrumentation using the generator alone or in a power bridge implementation. The purpose of these routines is to automate the testing procedures with the aid of the Switch Box (see sec. 2.4). As mentioned initially, these routines are not necessary for the basic operation of the generator and may be deleted if so desired. 


\subsubsection{Digit}

Because of its relative complexity, this subprogram has been separated into two parts, Digit (the $\mathrm{I} / \mathrm{O}$ portion) and Body (the measurement and error calculation portion).

To enter Digit, press the "DVM" (k1) function key. The screen is arranged into separate fields containing values that control both the execution flow and error calculations present in Body. Each column contains the complete set of variables required by Body to test the Power/Energy instrument at a single test point. Each row has the following meaning:

1. Serial \# When present, the name or number in this field serves two purposes: (1) to enable the channel for testing, and (2) to identify both the column on the screen and the test results printed on the printer.

2. Active After entering the meter's name or serial number in row 1, the field on this row Channels should fill with ${ }^{n * * * * n}$, which indicates that the corresponding switch box channel is to be included in the test.

3.\& 4. These rows indicate which type of tests are to be performed. The choices

Meas status are "VARS," "WATTS," "VAR HRS" and "WATT HRS."

5. Nominal The nominal voltage across a $1 \mathrm{k} \Omega$ standard resistor corresponding to the nominal Voltage $\quad 120 \mathrm{~V} \mathrm{rms}, 5 \mathrm{~A} \mathrm{rms}$, unity power factor output current/voltage of the meter under test.

6. Nominal The nominal pulse output of the meter under test at $120 \mathrm{~V} \mathrm{rms}, 5 \mathrm{~A}$ rms, unity Frequency power factor.

7. Voltage The meter's voltage (V) range setting.

Range

8. Current The meter's current (I) range setting.

Range

The contents of these fields are stored in the arrays Meas_str\$ and Meas_vals in the following way:

Meas_str $\$(1: 8,1: 6,0: 2)[8]$ :

$$
\begin{array}{ll}
(1, \mathrm{I}, 0)=\text { Serial number } & (4, \mathrm{I}, 1)=" \text { WATT HRS" } \\
(2, \mathrm{I}, 0)=" n & (5, \mathrm{I}, 0)=" 1.200000^{n} \\
(2, \mathrm{I}, \mathrm{I})=" * * * * " & (6, \mathrm{I}, 0)=" 277.7777^{n} \\
(3, \mathrm{I}, 0)=" \text { VARS " } & (7, \mathrm{I}, 0)=" 120.0 " \\
(3, \mathrm{I}, 1)=\text { "WATTS " } & (8, \mathrm{I}, 0)=" 5.0 " \\
(4, \mathrm{I}, 0)=\text { "VAR HRS" } &
\end{array}
$$

Meas_vals(1:9,1:6):

$$
\begin{array}{ll}
(1, \mathrm{x})=\text { Volt_nom } & (6, \mathrm{x})=\text { Dvm_avg } \\
(2, \mathrm{x})=\text { Count_nom } & (7, \mathrm{x})=\text { Count_avg } \\
(3, \mathrm{x})=\text { Diff_volt } & (8, \mathrm{x})=\text { Ppm_volt } \\
(4, \mathrm{x})=\text { Diff_count } & (9, \mathrm{x})=\text { Ppm_count }
\end{array}
$$

For an explanation of the Meas_vals values, see the table of MET_6 variables, APPENDIX A. 
The INTEGER array Scr_mat(1:8,1:6) serves as storage for indexes to the third dimension of the Meas_valS array. These indexes are then utilized by Digit to keep track of what to print in the chosen field and by Body for controlling its execution cycle.

To perform a test using Digit, the various parameters must be set up on the screen. First, enter the serial number of the meter under test (MUT) in row 1 of the column on the screen corresponding to the desired Switch Box channel. Move to this field by using the knob or arrow keys. When using the knob, the highlighted field will move in the direction of the last direction key hit. Once in the appropriate field the channel will not become active until the blinking serial number field is "ENTER"ed. At this point the field should stop blinking and a string of asterisks should appear below the serial number. Continue down the column until all parameters are set appropriately for the specific MUT. When in rows 3 and 4, the values in these fields may be changed by using the "[]" (k0) function key. Repeat this procedure for the remaining meter columns.

Column 6 on the screen is intended for the use of non-standard meters that have voltage rather than current outputs. When performing a power/energy measurement with the MUT's information entered in this column on the screen, Digit reads the dc output of the meter, not the value across the standard resistor.

The "DATA STORAGE $=$ " field indicates whether or not the error information printed on the printer is also to be stored on disk (see the "STORE DATA" (k9) softkey explanation below).

Once that all the screen parameters have been set up, push the "MORE" (k9) function key. The behavior of the remaining keys is as follows:

"PRINT MESSAGE" (k1): This routine will print the desired message on the measurement data printout. The message is saved in the array Message\$(1:5)[85] while inside Digit. To clear the displayed line, either "BACK SPACE" it off or use the "CLR LN" key. "ENTER"ing a blank line causes the message to be terminated and printed within the measurement data.

"PRINT HEADING" (k2): Pressing this key causes the header information to be printed.

"RESISTOR CORR" (k3): Digit usually uses a default value of $1 \mathrm{k} \Omega$ for the standard resistor value. This routine allows the user to enter the exact value of an available resistor. This value will be used in subsequent error calculations for all the active channels except the non-standard meter under test (NSMUT).

"DVM CORR" (k4): Pressing this key results in two choices, "10 V RANGE COR" (k1) or "1 V RANGE COR" (k6). These represent the error (in Ppm) of the HP 3456A when reading either $10 \mathrm{~V}$ dc or $1 \mathrm{~V}$ dc. Like "RESISTOR COR," these values will be used in subsequent error calculations for all the active channels including the non-standard meter under test (NSMUT).

"DUMP DATA" (k8): Pressing this key results in a catalog of the :INTERNAL,4,1 drive to be displayed along with a prompt asking for the desired filename. The only allowable files are BDAT files; all others will generate an error. The program interprets the contents of the file as ASCII characters and dumps them on the screen, so a file containing data of type 
"STORE DATA" (k9): This key enables or disables the subprogram's data storage option. When enabled, the "DATA STORAGE $=$ " field indicates "YES" and whatever is printed on the printer by the calibration subprogram is also stored as ASCII data in a file named according to the current date. For instance, the filename generated for the first file of Oct 2, 1955 would be "Oct255_1." Successive files for the same date are generated as the data buffer becomes full, i.e., "Oct255_2." This key must be enabled in order to enable an HPIB interrupt service routine within Digit called Send_to_pc (see discussion below).

Digit may also be configured to send error files to other computers over the IEEE-488 bus. Whenever the "DATA STORAGE $=$ " is enabled, Digit will service an SRQ interrupt using the routine "Sen_to_pc" and transfer specified files according to various parallel poll and serial poll responses. This routine is not enabled, however, whenever Digit is busy conducting a test.

\subsubsection{Guildline}

This subprogram is used to measure the $120 \mathrm{~V}$ rms signal of the voltage amplifier with the Guildline 7100A Thermal Transfer Standard. This subprogram may be reached from the main menu by using the "MORE" (k0) and "7100A" (k1) function keys. The user may select the number of readings to be performed at each of the four settings. The routine will sound a long, low-pitched beep when the setting of the Guildline requires changing. After being switched, the routine allows a settling time of 12 seconds. Once the Guildline has settled, the routine gives a noticeably higher-pitched, shorter beep that indicates it is beginning its measurements. The results of the measurement appear on the screen as ppm of reading based on a nominal value of $120 \mathrm{~V}$ rms.

\subsubsection{Ivd}

This routine is called from Status where its results are displayed on the screen and stored in the variables Rivd and Civd. These values correspond to the resistive and capacitive inductive divider settings that are required to balance the Power/Energy Bridge at the present phase angle, amplitude values, and frequency.

\subsubsection{Switch}

This is the switch box controller subprogram. Switch uses two input parameters: 1) Latch, the 8bit relay data word, and 2) Lat code, the integer value $(0-2)$ that determines which latch is loaded on the switch box. Table 2 is a list of the most frequently used parameter settings ( $\mathrm{X}=$ Don't Care). 


\begin{tabular}{|c|c|c|c|}
\hline INPUT & OUTPUT & Latch & \\
\hline \multirow[t]{3}{*}{ MUT1 } & \multirow[t]{3}{*}{ HP DVM } & $62(00111110)$ & $1(\mathrm{U} 4)$ \\
\hline & & $0(\mathrm{XXXXXX00)}$ & 2(U1) \\
\hline & & $32(\mathrm{XX10XXXX)}$ & $0(\mathrm{U} 2 \& \mathrm{U} 3)$ \\
\hline MUT1 & HP Cntr & $240(1111 X X X X)$ & 2(U1) \\
\hline \multirow[t]{3}{*}{ MUT2 } & \multirow[t]{3}{*}{ HP DVM } & $93(01011101)$ & 1 \\
\hline & & $0(\mathrm{XXXXXX00)}$ & 2 \\
\hline & & $32(\mathrm{XX10XXXX)}$ & 0 \\
\hline MUT2 & HP Cntr & $224(0111 X X X X)$ & 2 \\
\hline \multirow[t]{3}{*}{ MUT3 } & \multirow[t]{3}{*}{ HP DVM } & $155(10011011)$ & 1 \\
\hline & & $0(\mathrm{XXXXXX00)}$ & 2 \\
\hline & & $32(\mathrm{XX10XXXX)}$ & 0 \\
\hline MUT3 & HP Cntr & 208(1011XXXX) & 2 \\
\hline \multirow[t]{3}{*}{ MUT4 } & \multirow[t]{3}{*}{ HP DVM } & $23(00010111)$ & 1 \\
\hline & & 1(XXXXXX01) & 2 \\
\hline & & $32(\mathrm{XX10XXXX)}$ & 0 \\
\hline MUT4 & HP Cntr & 192(0011XXXX) & 2 \\
\hline \multirow[t]{3}{*}{ MUT5 } & \multirow[t]{3}{*}{ HP DVM } & $15(00001111)$ & 1 \\
\hline & & $2(\mathrm{XXXXXX10)}$ & 2 \\
\hline & & $32(\mathrm{XX10XXXX)}$ & 0 \\
\hline MUT5 & HP Cntr & 176(1101XXXX) & 2 \\
\hline NSMUT & HP DVM & $16(\mathrm{X} 0 \mathrm{X} 10 \mathrm{XXX})$ & 0 \\
\hline GENERATOR & HP DVM & $0(0 \mathrm{X} 00 \mathrm{XXXX})$ & 0 \\
\hline REF-OFFSET & & & \\
\hline GENERATOR & HP DVM & $128(1 \mathrm{X} 00 \mathrm{XXXX})$ & 0 \\
\hline \multicolumn{4}{|c|}{ VAR-OFFSET } \\
\hline GUILDLINE & HP DVM & $80(X 1 X 10 X X X)$ & 0 \\
\hline I-AMP & HP DVM & $24(X X X 11 X X X)$ & 0 \\
\hline V-AMP & HP DVM & $0(\mathrm{XXXXX0XX)}$ & 0 \\
\hline
\end{tabular}




\subsubsection{Dec_to_bin}

This is a recursive subprogram that converts the input parameter Quotient into a string representation, String\$, of the binary equivalent. Dec_to_bin is mainly used in the Amplitude subprogram, where it is used to display the 18-bit DAC word for amplitude. The main purpose of the routine is for the debugging of control routines. A command that performs this same task is included in some versions of HP BASIC.

\subsubsection{Enable}

This routine calls Switch to enable or disable the voltage amplifier, depending on the global variable, V_amp.

\subsubsection{Print_time}

This is a routine used to print the time and date. After using the "MORE" (k0) key in the main function key menu, Print_time is called every second to update the time and date located in the upperright of the screen.

To set the time, use the "MORE" and "SET TIME" (k2) keys. Likewise, to set the date, use the "MORE" then "SET DATE" keys.

\section{GENERATOR OUTPUT BOARD ADJUSTMENT}

Each of the digital generator's two output boards contains two trim pots that must be adjusted (Pot(i) and Pot(ii) on fig. 7). The following steps are required to properly adjust each of the generator's output boards:

(i) Set the amplitude (Ref_amp or Var_amp) to zero. To do this from the main function key menu, use the "AMP." (k8), "REF WAVE" (k1) or "VAR WAVE" (k6), and finally "AMP" function keys. Next, exit this routine and enter Cor dac to alter the "LINEARITY" value (see sec. 3.3.1.3). This routine alters the dc offset voltage of the amplitude DAC (U9 on fig. 7). Adjust the 8-bit MDAC until point A is as close to zero as possible. Make sure to note or store this value of $\mathrm{R}(\mathrm{V})$ _u 9 _offst using the "STORE VALUES $^{n}$ (k4) key.

(ii) Set the amplitude to full scale. To do this, enter the Amplitude subprogram and increase the voltage (current) until the "ACTUAL" binary string on the lower left of the screen reads all ones. Now, adjust Pot(i) until point $\mathrm{A}$ equals approximately $10 \mathrm{~V} \mathrm{dc}$.

(iii) With the amplitude (Ref_amp or Var_amp) still set to all ones, enter Wav_gen (see sec. 3.3.3.9) and set the proper memory channel to all zeroes. Now set the dc offset voltage (point B on fig. 7) of the output dac (U8 on Output Board) to zero using Cor_dac in the "OFFSET" mode (see sec. 3.3.1.3).

(iv) Finally, with the amplitude still at full scale, use Wav gen to load all ones into the appropriate memory channel and adjust Pot(ii) until point B equals approximately $10 \mathrm{~V} \mathrm{dc}$. 


\section{GENERATOR CHARACTERIZATION}

MET_6 provides for the characterization and correction of the generator's dc offset voltage, waveform amplitude, and the transconductance amplifier compliance voltage errors. Although the subprogram Calibrate is intended mainly for formatting plot data for a plot program, it can also be used for characterizing the generator.

The first step is to adjust the generator's output boards (see sec. 4 above). Second, before performing any runs with Calibrate, all correction terms should be zeroed. This may be accomplished by pausing the program and typing "CALL MACHINE_STATE $(-1)^{n}$ and then "EXECUTE."

The remaining procedures for characterizing each of the mentioned parameters are fairly similar and straightforward.

\subsection{Dc Offset Voltage}

Enter the Calibrate subprogram and choose either the "V-AMP OFFSET LINEARITY" or "IAMP OFFSET LINEARITY" rows. In the secondary menu, set the parameters to appropriate values if the default ones are incorrect. Connect the output of the desired channel to the DVM and use the "SELECT > OPTION" function key. The Measure subprogram will then call Offset_zero at each test point and store the values $\mathrm{R}(\mathrm{V}) \mathrm{o}_{-}$intercept and the applied voltage/current in the chosen ASCII file. NOTE: Offset_zero expects the dc offset of the variable channel to be inverted, so either the output monitor of the transconductance amplifier or the inverted sense of the generator's variable channel output must be used. Finally, retrieve these values and perform a linear fit to find $\mathrm{R}(\mathrm{V}) \mathrm{O} \_$slope and $\mathrm{R}(\mathrm{V}) \mathrm{O}$ intercept.

\subsection{Amplitude}

With $\mathrm{R}(\mathrm{V})$ _slope and $\mathrm{R}(\mathrm{V}) \_$intercept still equal to zero, enter the Calibrate subprogram and use either the "V-AMP INTEGRAL LINEARITY" or "I-AMP INTEGRAL LINEARITY" rows. Both the error (in ppm of full scale) and the nominal voltage are stored in the chosen ASCII file. A linear fit will probably return values for $\mathrm{R}(\mathrm{V})$ _slope and $\mathrm{R}(\mathrm{V})$ _intercept that are slightly in error due to the waveform's amplitude errors result in gain correction errors. To avoid the above problem, another method of characterizing the gain is to zero the gain errors at several points, note $\mathrm{R}(\mathrm{V})$ _intercept at each point and use a linear fit to calculate the proper $\mathrm{R}(\mathrm{V}) \_$slope and $\mathrm{R}(\mathrm{V})$ _intercept.

\subsection{Transconductance Amplifier Compliance Voltage}

Since the Calibrate subprogram does not provide a compliance correction mode, the values for $\mathrm{C}_{-}$slope and $\mathrm{C}_{-}$intercept may be found using the following method. First, zero $\mathrm{C}_{-}$slope, $\mathrm{C}_{-}$intercept and C_ppm as described above. Now, use the "COMPLIANCE" subprogram (see sec. 3.3.1) at 5 A rms to find the proper $C_{-}$intercept for several different transconductance amplifier burden conditions. The resulting linear fit should provide adequate values for $C_{-}$intercept and $C_{-}$slope. 


\section{SYSTEM PERFORMANCE AND CONCLUSIONS}

\subsection{System Performance}

The power source was originally intended to operate at $60 \mathrm{~Hz}$ with $120 \mathrm{~V}$ and $5 \mathrm{~A}$ sinusoidal waveforms. However, the present source is programmable between $0-240 \mathrm{~V}$ and $0-5 \mathrm{~A}$ with sinusoidal as well as arbitrary waveforms at frequencies from $0.001 \mathrm{~Hz}$ to $100 \mathrm{kHz}$. These figures represent the limits of amplitude and frequency. Measurements, described in this paper, were performed at $60 \mathrm{~Hz}$ and at amplitudes between $20-100 \%$ of full scale (FS). The amplitude and phase angle errors given below were obtained by measuring the source using a thermal wattmeter [10] and a current-comparator power-bridge [11].

The amplitudes of the reference and variable channels are changed by adjusting the dc voltages supplied to MDAC1 and MDAC2. However, the output voltages $V_{1}$ and $V_{2}$ are not ideal linear functions of these dc voltages and thus a gain adjustment is required at different amplitudes. Software gain corrections for any amplitude (based on a linear fit to a few data points) reduce this voltage dependent gain error by a factor of 5-10. Figure 16 shows the residual amplitude nonlinearity, after correction, over a 5 to 1 amplitude range where $100 \%$ of FS represents $240 \mathrm{~V}$ and 5 A respectively. Differential nonlinearity around 120 volts and 5 amperes is shown in figure 17 . The sample points represent a one least-significantbit change (4 ppm of FS) of the respective scaling DACs.

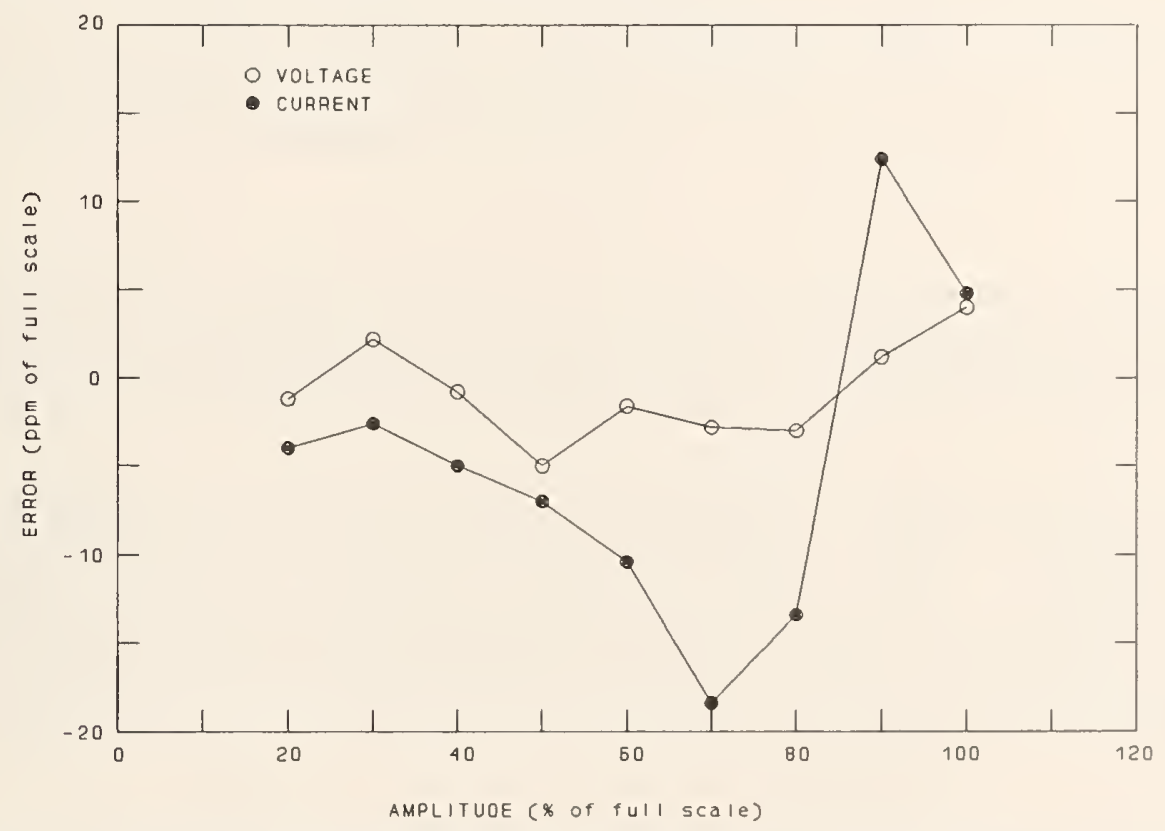

Figure 16. Residual voltage and current integral nonlinearity after gain corrections.

Phase angle accuracy depends upon the initial offset (differential phase shift between channels) and the phase linearity, which is a function of quantization errors, DAC nonlinearity, and the number of steps per period. The initial phase offset between the voltage and current waveforms was measured by the current comparator power bridge and adjusted to zero at unity power factor $\left(0^{\circ}\right)$ with an uncertainty of less than 10 microradians. 
Subsequent power measurements, with constant voltage and current, between $+90^{\circ}$ and $-90^{\circ}$, indicate that the integral phase nonlinearity in this range is less than 20 microradians.

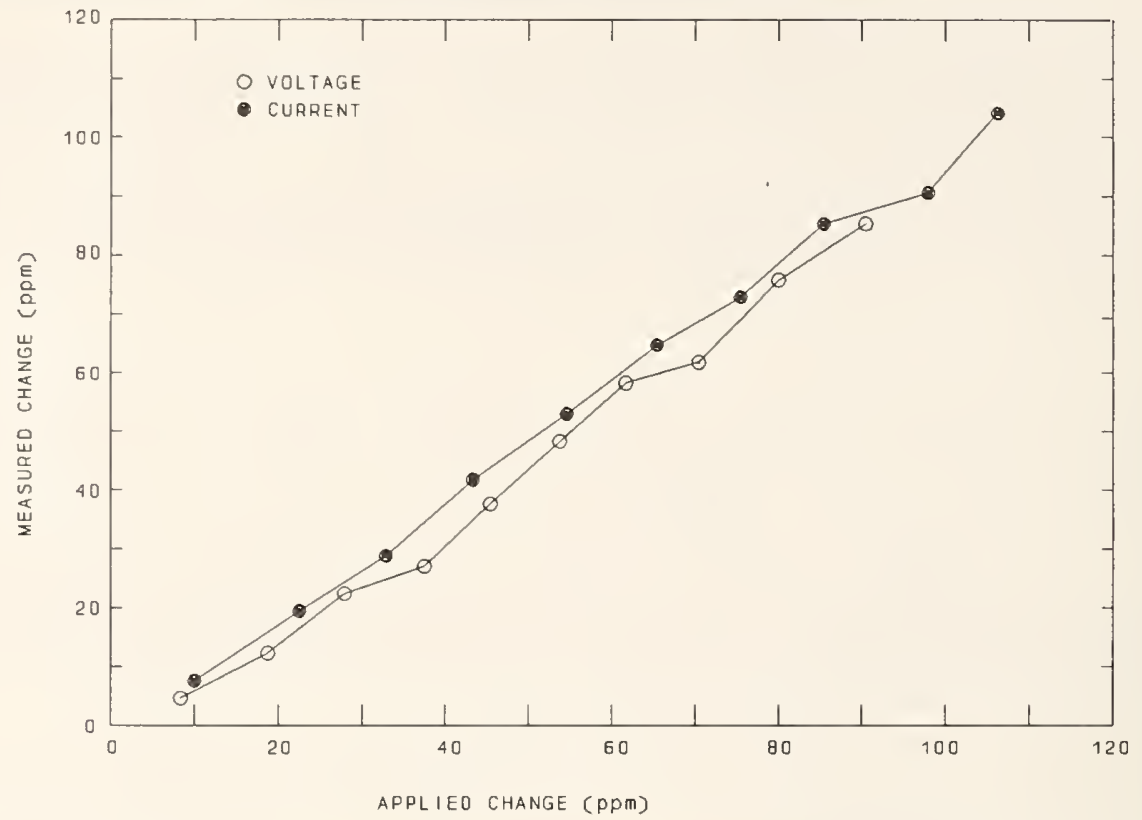

Figure 17. Voltage and current differential nonlinearity around $120 \mathrm{~V}$ and $5 \mathrm{~A}$.

Figure 18 shows the differential phase linearity at zero power factor $\left(90^{\circ}\right)$ as measured by a timedivision-multiplier (TDM) wattmeter [12]. This plot not only confirms the computer simulation predictions of 1 microradian phase resolution of the digital generator, but demonstrates the potential of TDM wattmeters for performing extremely precise measurements around zero power factor as well.

Once the three parameters (voltage, current, and phase angle) have been adjusted and corrected, the major concern becomes stability. Measurements at $120 \mathrm{~V}, 5 \mathrm{~A}$ over a three week period are given in figure 19. The precision of these measurements was approximately $10 \mathrm{ppm}$ in amplitude and 10 microradians in phase. The current drift of $80 \mathrm{ppm}$ has been attributed to aging of the $0.1 \mathrm{ohm}$ shunt in the transconductance amplifier. A simple dc calibration of this amplifier is useful in detecting the gain drift due to the shunt and the results may be applied as an additional gain correction to improve long-term current stability.

Finally, the source was evaluated over a three week period as a power calibrator. Measurements were performed at $120 \mathrm{~V}$ and $5 \mathrm{~A}$ at a number of phase angles between $\pm 90^{\circ}$. The source was adjusted at the beginning of the testing period and used to calibrate a TDM wattmeter over the next 20 days without further adjustments. Measurements were also performed on the TDM wattmeter using the power bridge, and an envelope which encloses all of the differences between the source and the bridge, using the TDM wattmeter as a transfer standard, is plotted in figure 20. There is a direct correlation between these differences and the current drift from figure 19 as the data for both plots were collected during the same period. If corrected for this drift, the maximum power differences fall within a $\pm 30 \mathrm{ppm}$ band, as shown in figure 21. These figures include the short-term drift of the TDM wattmeter between the source and bridge calibrations. 


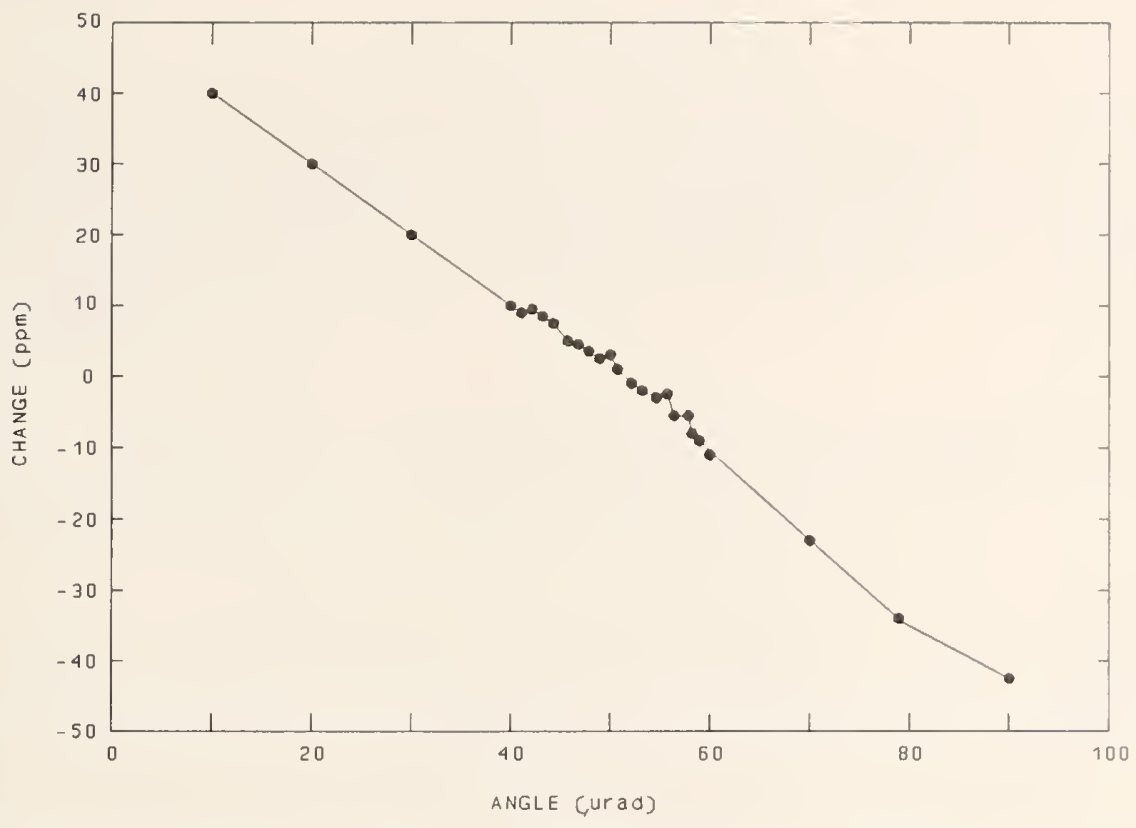

Figure 18. Phase differential nonlinearity - generator angle vs change in power indication of a TDM wattmeter at zero power factor.

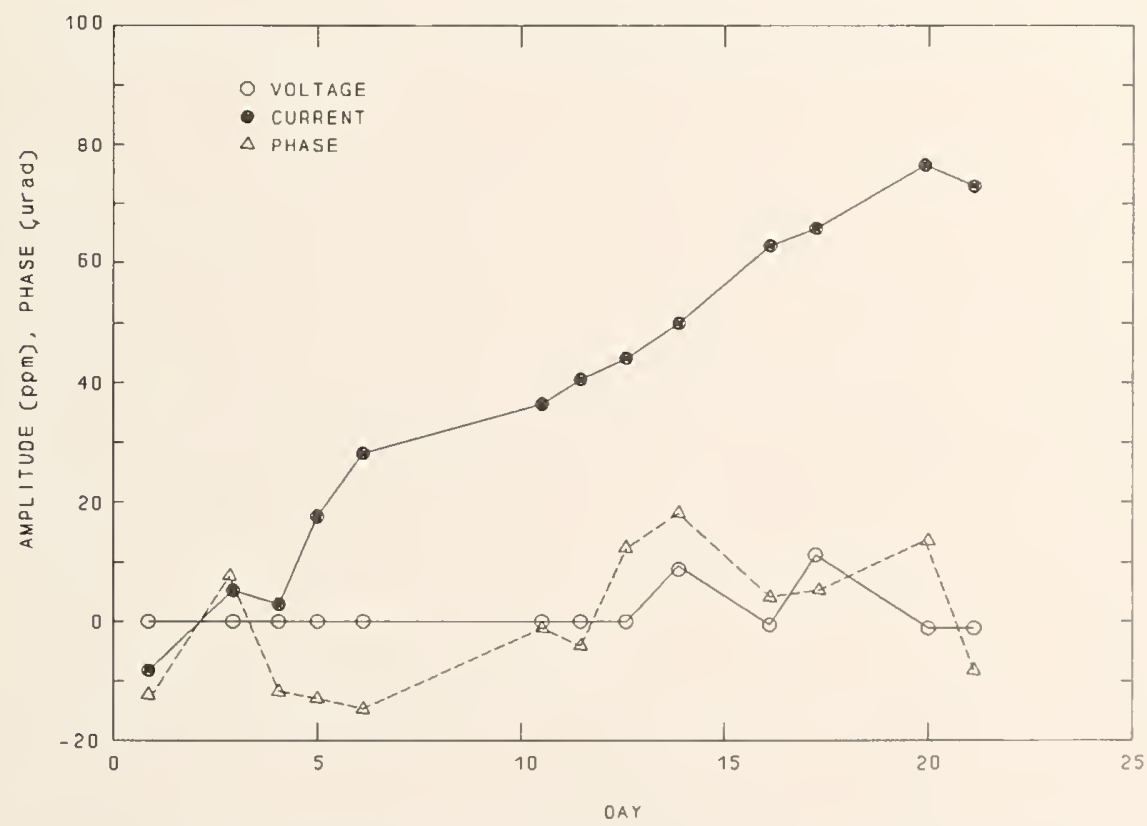

Figure 19. Long term stability of the source voltage, current, and phase angle as measured by a thermal wattmeter. 


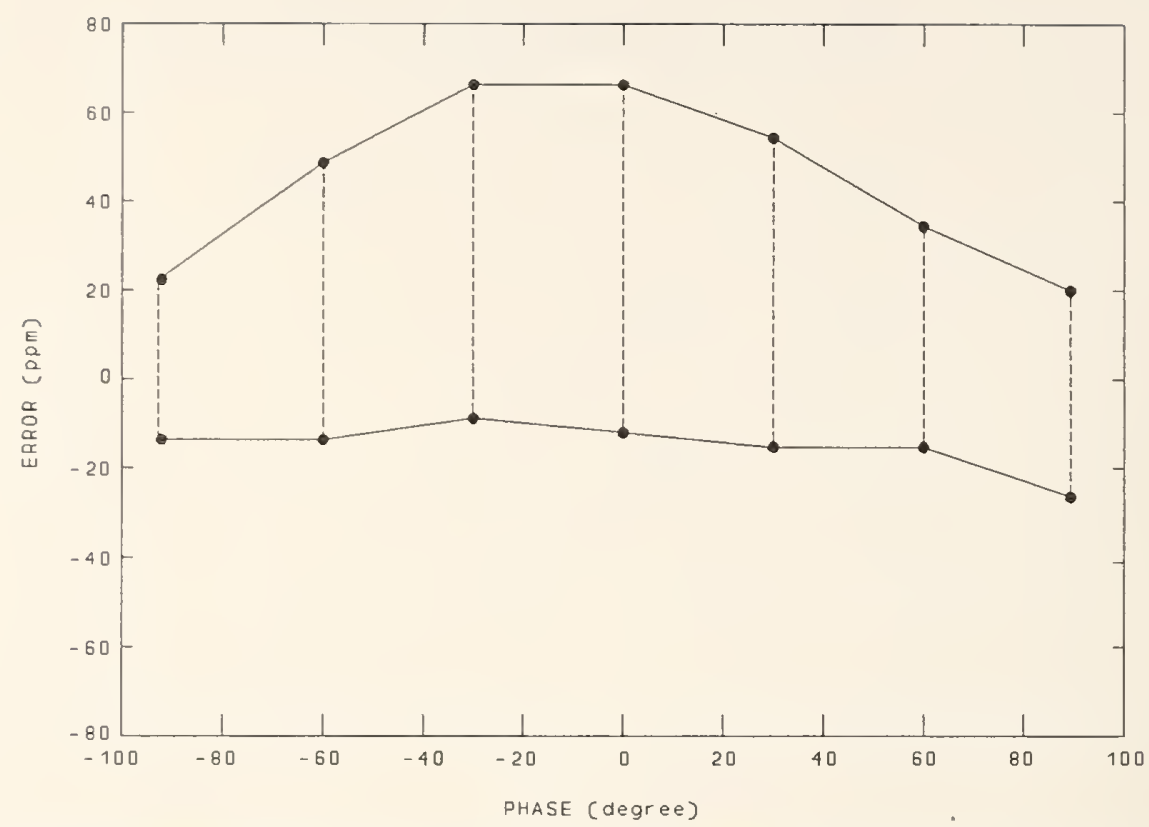

Figure 20. Maximun differences between the power calibration source and the power bridge using a TDM wattmeter as a transfer standard.

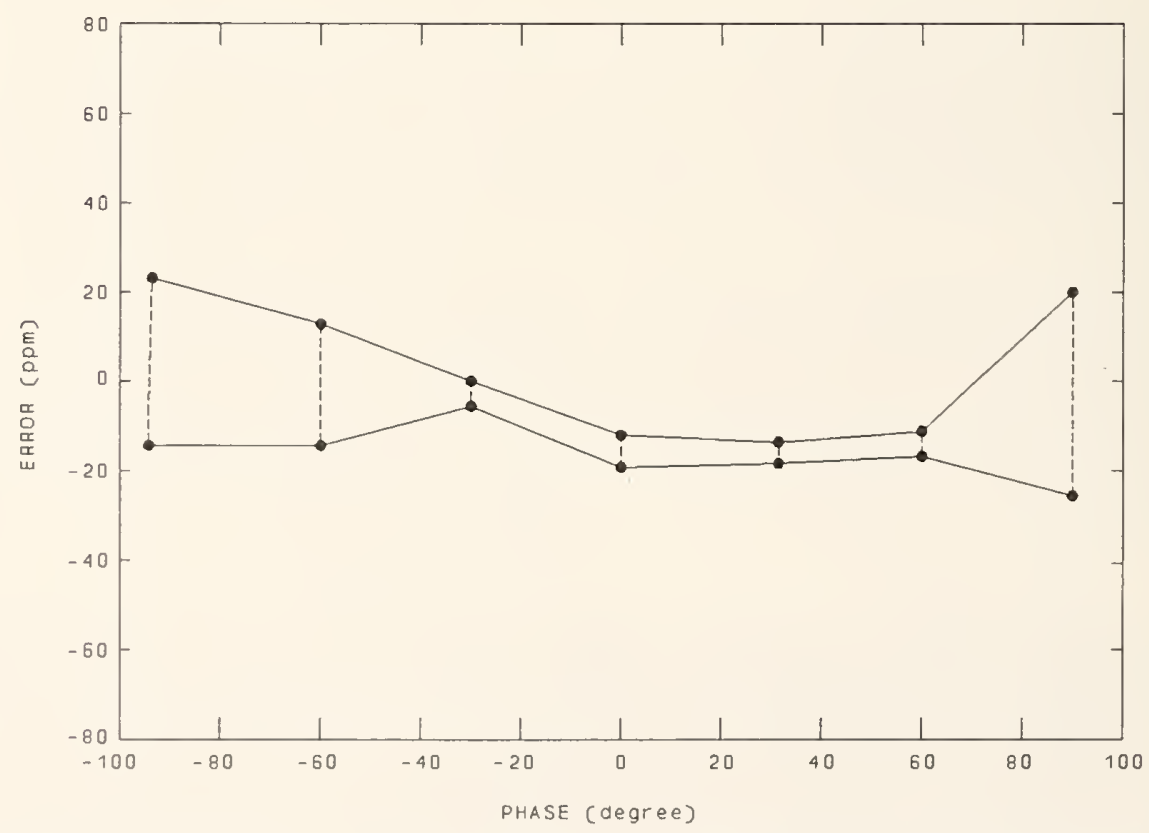

Figure 21. Maximum differences between the power calibration source and the power bridge after correcting for the current drift. 


\subsection{Conclusions}

An accurate and precise source of synthetic power for calibrating watt/watthour and var/varhour meters at the $100 \mathrm{ppm}$ level has been described. The source consists of a dual-channel digital waveform generator followed by direct-coupled high-voltage and transconductance amplifiers to provide signal levels of 60-240 V and 1-5 A at any phase angle. Control is provided by a desk-top computer and auxiliary instrumentation supports the calibration of up to six test instruments. The uncertainties of source parameters at power frequencies are:

1. voltage $<30 \mathrm{ppm}$ of $\mathrm{FS}$.

2. current $<50 \mathrm{ppm}$ of FS (requires a periodic monitor of the current amplifier gain).

3. phase $<20$ microradians at FS voltage and current (degrades slightly at lower amplitudes).

4. Power (active and reactive) $<100 \mathrm{ppm}$ of FS volt-amperes.

While the source is normally operated under sinusoidal conditions, future applications will utilize its ability to synthesize arbitrary waveforms with dc components. A direct coupled system permits calibration of gain factors at $\mathrm{dc}$ where, in general, the resolution and accuracy of measuring instrumentation is greater. Extrapolating results at dc to power frequencies is reasonable and offers the possibility of a

calculable ac source based on dc measurements. Furthermore, experience with a direct-coupled system has focused attention on the ever present ground loops that always seem to evolve in a system. In fact, monitoring and eliminating dc offsets created by ground loops has turned out to be a good technique for assuring that ground loops do not create measurement errors which might otherwise go undetected. 


\section{REFERENCES}

[1] J. R. Kinard and L. A. Harris, "Wattmeter Calibration at Zero Power Factor Using Digitally Generated Sinewaves," IEEE Trans. on Instrum. Meas., IM-25, No. 4, Dec. 1976.

[2] R. S. Turgel and N. M. Oldham, "High-Precision Audio-Frequency Phase Calibration Standard," IEEE Trans. on Instrum. Meas., IM-27, No. 4, Dec. 1978.

[3] N. M. Oldham and R. S. Turgel, "A Power Factor Standard Using Digital Waveform Generation," IEEE Trans. on PAS, Vol. PAS-100, No. 11, Nov. 1981.

[4] C. Vastrade, R. DeVre, M. Couvreur, and R. Huybrechts, "Calibration of High Accuracy Wattmeters with a Standard Generator," IEEE Trans. on Instrum. Meas., IM-34, No. 2, June 1985.

[5] H. Ahlers, L. Rahf, H. Hartwig, and J. D. Sievert, "Programmable Digital Two-Channel Function Generator for Testing Power Meters," IEEE Trans. on Instrum. Meas., IM-34, No. 2, June 1985.

[6] N. M. Oldham, "A Power Calibration Standard Based on Digitally Synthesized Sinewaves," IEEE Trans. on PAS, Vol. PAS-104, No. 11, Nov. 1985.

[7] O. B. Laug, "A Precision Power Amplifier for Power/Energy Calibration Applications," IEEE Trans. on Instrum. and Meas. IM-36, No. 4, Dec. 1987.

[8] O. B. Laug, "A Wide-Band Transconductance Amplifier for Current Calibrations," IEEE Trans. on Instrum. Meas., IM-34, No. 4, Dec. 1985.

[9] R.S. Turgel, "A Precision Phase Angle Calibration Standard for Frequencies up to $50 \mathrm{kHz}$," IEEE Trans. Instrum. Meas., vol. IM-34, no. 4, pp. 509-516, December 1985.

[10] G. Schuster, "Thermal Instrument for Measurement of Voltage, Current, Power, and Energy at Power Frequencies," IEEE Trans. Instrum. Meas., vol. IM-29, no. 3, Sept. 1980.

[11] N. M. Oldham and O. Petersons, "Calibration of Standard Wattmeters using a Capacitance Bridge and a Digital Generator," IEEE Trans. Instrum. Meas., vol. IM-34, no. 4, Dec. 1985.

[12] P. Miljanic, B. Stojanovic, and P. Bosnjakovic, "The Development of a High Precision TimeDivision Power Meter," in CPEM 84 Dig., Proc. Conf. Precision Electromagnetic Meas. (Delft, the Netherlands), 1984, pp. 67-68. 
APPENDIX A: Table of Met_6 Variables 

Name

@Buffer

(a)_ref

@C_var

@Counter

@Dvm

(a) Gpio

$@ \mathrm{Kbd}$

@Meter

@Storage

A

A

A(2048)

A1

A1

A1

A2

A2

A. 3

Aborted

Ac_or_dc

Act_string\$[20]

Actual
Type*

$\mathrm{P}$

P

P

P

$\mathrm{P}$
$\mathrm{P}$

P

$\mathrm{P}$

P

P

R

R

R

R

R

R

R

R

$\mathrm{R}$

I

I

$\$$

$\mathrm{R}$
APPENDIX A: Table of Met_6 Variables

Description

Input parameter of various subprograms

that holds the $\mathrm{I} / \mathrm{O}$ path designator for

either the Coarse_ref( $\left.{ }^{*}\right)$ or Coarse_var( $\left.{ }^{*}\right)$

INTEGER Buffers.

I/O path designator for the INTEGER

Buffer, Coarse_ref(*).

I/O path designator for the INTEGER

Buffer, Coarse_var( $\left.{ }^{*}\right)$.

I/O path for the HP 5384A Freq. Counter. Main

I/O path for the HP 3456A Dvm.

I/O path for the GPIO interface.

I/O path for the keyboard. Used for

outputing special keys to the keyboard

such as Clear_crt\$.

I/O path for either the HP 3456A, FLUKE 8506 A, or Hamburger K2004.

I/O path for the ASCII file, Met6vals.

The number of $(1 / 2048)$ steps correspond-

ing to the computed Di_ff.

Most significant 8-bits of the computed Ivd setting.

Matrix used to compute the Rms value of the chosen waveform.

The generator's interface board address

for enabling the most significant 8-bit latch of the desired Ivd.

Top 8-bits of the uncorrected amplitude.

The truncated number of $(1 / 2048)$ steps

corresponding to the computed Di_ff.

The fractional portion of the number of (1/2048) steps corresponding to Di_ff.

Top 8-bits of the gain-corrected amplitude word. Does not include compliance correction.

Rop 8-bits of the fully corrected amplitude word. Includes all corrections.

I Flag indicating that too many bus errors have occurred. If Aborted $=1$, then Digit terminates as soon as possible.

Flag indicating that the chosen meter is to measure ac (1) or dc (0) values. Holds the string representation of the present 18-bit amplitude dac setting. The computed amplitude of the relevant channel including all corrections.
Found In:

Out_put

Init

Main

Main

Main

Main

Main

Measure

Main

Change_phase

Ivd

Init

Ivd

Amplitude

Change_phase

Change_phase

Amplitude

Amplitude

Digit

Measure

Amplitude

Amplitude

* $\mathrm{B}=$ Buffer, $\mathrm{I}=$ Integer, $\mathrm{P}=\mathrm{I} / \mathrm{O}$ Path, $\mathrm{R}=$ Real, $\mathrm{S}=$ String 
Name

Actual_resistor

Address_add

All_blanks

AlphaS[2]

Angle

Applied

Av_num

Average

B

B1

B1

$\mathrm{B} 2$

B3

Bage $[80]$

Blink

Bot_row

Bus_error
Add_bits

Type

$\mathrm{R}$

$\mathrm{R}$

Input parameter of the address increment corresponding to the present phase difference. Passed on to Cnt_vals.

$R$. Input parameter of the address increment corresponding to the present phase difference.

I Flag set to 1 if the field being manipulated is presently all blanks.

$\$ \quad$ Non ASCII key sequence output to the keyboard that sets the crt into alpha mode.

$\mathrm{R} \quad$ Input parameter representing the desired phase angle.

$\mathrm{R} \quad$ Local variable representing the nominal value of interest.

I Measurement averaging counter.

$\mathrm{R}$ Average of the Guildline 7100A measurements.

R 2nd 8-bits of the 24-bit programmable Ivd.

$\mathrm{R}$ The generator's interface board address for enabling the 2nd slice 8-bit latch of the proper Ivd.

$\mathrm{R}$ 2nd 8-bits of the uncorrected amplitude.

$\mathrm{R}$ 2nd 8-bits of the gain-corrected amplitude dac word.

$\mathrm{R}$ 2nd 8-bits of the fully corrected amplitude dac word. Includes all corrections.

S Entry string for the date. (see Date_Main set:).

I Flag set to 1 if the field of interest is to be blinking.

$\mathrm{R} \quad$ Defines the last permissible menu row.

I Flag indicating the cause of a timeout.

$=0$ : Hpib RESET timeout.

$=1$ : Dvm configuration timeout.

$=2$ : Counter config. timeout.

=3: Dvm Status Register config. timeout.

=4: Counter Status Register config. timeout.

=5: Timeout on returning Dvm and counter to local.

C 3rd 8-bit slice of the 24-bit Ivd setting.
Found In:

Main

Out_put

Cnt_vals

Digit

Main

Change_phase

Adj_phase

Measure

Measure

Guildline

Ivd

Ivd

Amplitude

Amplitude

Amplitude

Digit

Calibrate

Digit

Ivd 


\begin{tabular}{|c|c|c|c|}
\hline Name & Type & Description & Found In: \\
\hline$C_{-}$intercept & $\mathrm{R}$ & $\begin{array}{l}\text { Intercept of the Transconductance } \\
\text { Amplifier's linear compliance correction } \\
\text { curve. }\end{array}$ & Main \\
\hline C_ppm & $\mathrm{R}$ & $\begin{array}{l}\text { Ppm (of reading) correction calculated } \\
\text { from C_slope and C_ppm that is added to } \\
\text { variable channel amplitude dac settings. }\end{array}$ & Main \\
\hline C_slope & $\mathrm{R}$ & $\begin{array}{l}\text { Slope of the Transconductance Ampli- } \\
\text { fier's linear compliance correction } \\
\text { curve. }\end{array}$ & Main \\
\hline $\mathrm{C} 1$ & $\mathrm{R}$ & $\begin{array}{l}\text { The generator's interface board address } \\
\text { for enabling the 3rd 8-bit latch of the } \\
\text { desired Ivd. }\end{array}$ & Ivd \\
\hline $\mathrm{C} 1$ & $\mathrm{R}$ & $\begin{array}{l}\text { Last 2-bits of the uncorrected ampli- } \\
\text { tude. }\end{array}$ & Amplitude \\
\hline$C 2$ & $\mathrm{R}$ & $\begin{array}{l}\text { Last 2-bits of the gain-corrected } \\
\text { amplitude dac word. Does not include } \\
\text { the compliance correction. }\end{array}$ & Amplitude \\
\hline $\mathrm{C} 3$ & $\mathrm{R}$ & $\begin{array}{l}\text { Last 2-bits of the fully corrected } \\
\text { amplitude dac word. All corrections. }\end{array}$ & Amplitude \\
\hline Cal_int_vals $(10,5)$ & I & $\begin{array}{l}\text { Array set up in Calibrate and used by } \\
\text { Measure to control its execution flow. } \\
\text { For an explanation of its contents, see } \\
\text { section 3.4:3. }\end{array}$ & Main \\
\hline Cal_r_vals $(10,6)$ & $\mathrm{R}$ & $\begin{array}{l}\text { Array set up in Calibrate and used by } \\
\text { Measure to control its execution flow. } \\
\text { For an explanation of its contents, see } \\
\text { section 3.4.3. }\end{array}$ & Main \\
\hline Calib_val\$(12,4)[30] & $\$$ & $\begin{array}{l}\text { Array set up in and used by Calibrate } \\
\text { to operate its menu. For an explana- } \\
\text { tion of its contents, see section 3.4.3. }\end{array}$ & Main \\
\hline Cap & $\mathrm{R}$ & $\begin{array}{l}\text { Scale factor used to calculate Civd, the } \\
\text { Capacitive Ivd setting. }\end{array}$ & Ivd \\
\hline Cha_nge & $\mathrm{R}$ & $\begin{array}{l}\text { Value used in the Interactive } \mathrm{I} / \mathrm{O} \text { rou- } \\
\text { times that represents the change, in } \\
\text { terms of smallest divisible units, } \\
\text { between the value at time of entry and } \\
\text { the present value. Cha nge is scaled } \\
\text { so that it is easily displayed. }\end{array}$ & $\begin{array}{l}\text { Adj_phase } \\
\text { Synth_load }\end{array}$ \\
\hline Change & $\mathrm{R}$ & $\begin{array}{l}\text { The unscaled equivalent to Cha_nge, } \\
\text { discussed above. }\end{array}$ & $\begin{array}{l}\text { Adj_phase } \\
\text { Cor_dac } \\
\text { Synth_load }\end{array}$ \\
\hline Changed & I & $\begin{array}{l}\text { Flag that is set to } 1 \text { if the amplitude } \\
\text { value of the reference channel crosses } \\
\text { the } 7.07 \mathrm{Vrms} \text { boundary. In which case } \\
\text { the } V \text {-amp is either enabled or disabled. }\end{array}$ & Amplitude \\
\hline Changed & I & $\begin{array}{l}\text { Flag that is set to } 1 \text { if the phase } \\
\text { resolution changes (Sel_ect changes). }\end{array}$ & Adj_phase \\
\hline
\end{tabular}


Name

ChannelS[7]

Check

Choices

Civd

Clear_crt\$[2]

Cntr_flag

Coarse_ref(2048)

Coarse_var(2048)

$\mathrm{Col}$

Col_index

Col_max

Column

Column1

Comp_volts

Constant

Cosine

Count

Counter
Type

$\underline{\text { Description }}$

$\$$

String containing either "VOLTAGE" or

"CURRENT" depending on which output board is being addressed.

I If Check $=1$ then Init does not print the documentation title and revision message.

$\$ \quad$ String containing either "GAIN", "OFFSET" or "LINEAR" depending on Dac_choice.

$\mathrm{R}$ The setting of the capacitive Ivd.

S Non ASCII key sequence that is output to the keyboard and clears the CRT.

I Flag set to 1 in the subroutine, Intr_ service, after the counter requests service.

B Buffer used to store and transfer the 2048 waveform data points to the generator's reference channel memory.

B Buffer used to store and transfer the 2048 waveform data points to the generator's variable channel memory.

I Used in various routines to keep track of the display column of that routine.

I Index to the second dimension of Calib val\$ $(12,4)[30]$. See section 3.4.3.

Set according to the page of the menu.

I Maximum number of columns allowable in the Digit subprogram.

I The present column, regardless of the menu page, that is used in the TABXY PRINT statements.

I Variable to keep track of the 1st menu's Column variable.

$\mathrm{R} \quad$ Value read by the HP 3456A (the ac compliance voltage of the Transconductance Amplifier).

$\mathrm{R} \quad$ Constant (Usually 5.0) that is added to the desired offset or linearity voltage that is then added to the 8-bit dac word so that the value is direct reading.

$\mathrm{R}$ Constant (the COS(Phaz)) that is used in Ivd to calculate Rivd, the resistive Ivd setting.

I The number of measurements performed on the present Guildline setting.

$\mathrm{R} \quad$ The measured pulse output of the MUT.
Found In:

Amplitude

Init

Cor_dac

Ivd, Main

Main

Digit

Main

Main

Calibrate

Digit

Calibrate

Main

Calibrate

Calibrate

Compliance

Cor_dac

Ivd

Guildline

Digit 
$\underline{\text { Name }}$

Dac_choice

Date\$

Dec_pt_mask

Decimal\$[2]

Device\$

Di_ff

$\operatorname{Diff}(*)$

Diff_applied

Diff_meas

Direction

Done

Done_once

Dont_store

Dvm_corr_high

Dvm_corr_low
Type

I

The input parameter of Cor_dac which determines which output board function is manipulated.

$=0:$ LINEARITY

$=1$ : DC OFFSET

=2: GAIN

String used to print the current date on the upper right of the screen.

Used to calculate the decimal point scale factor of the Hamburger K2004 output data.

\$ Used to calculate Dec_pt_mask.

$\$ \quad$ Value set by Calibrate that determines

which meter is to be used in the Measure

run.

$\mathrm{R} \quad$ The difference (in degrees) between the variables Phaz and Offst. This value is then used as an input parameter to Cnt_vals (Sel_ect $=1$ ) or as a scale factor to calculate the new variable channel waveform values (Sel_ect $=2$ ).

$\mathrm{R} \quad$ Real array containing the differences between consecutive Real(*) array values. $\operatorname{Real}\left({ }^{*}\right)$ and $\operatorname{Diff}\left({ }^{*}\right)$ are then used to calculate the new INTEGER buffer values.

$\mathrm{R} \quad$ Value used in differential nonlinearity calibrations for calculating errors.

$\mathrm{R} \quad$ Used in conjunction with Diff_applied to calculate the differential errors.

I Used by several routines to store the last arrow key that was hit. The knob will then move in this direction until a different direction key is hit.

I Used in various interrupt service routines. If Done $=1$ then the interrupt has been serviced.

I Flag indicating that a certain subroutine has been branched to once already. If Done_once $=1$, the subprogram is usually aborted.

I Flag used in error storage subroutines which indicates that no data is to be stored.

$\mathrm{R}$

Dvm-measured value correction to compensate for Dvm errors. Used in Digit for $10 \mathrm{Vdc}$ range error calculations.

$\mathrm{R} \quad$ Dvm_measured value correction to compensate $\bar{f}$ or Dvm errors. Used in Digit for $1 \mathrm{Vdc}$ range error calculations.
Found In:

Cor_dac

Main

Measure

Measure

Measure

Change_phase

Init

Measure

Measure

Process_key

Digit

Measure

Digit

Digit

Measure

Main

Main 


\begin{tabular}{|c|c|c|c|}
\hline$\underline{\text { Name }}$ & Type & Description & Found In: \\
\hline Dvm_flag & I & $\begin{array}{l}\text { Flag set to } 1 \text { in the subroutine, Intr_ } \\
\text { service, after the counter requests } \\
\text { service. }\end{array}$ & Digit \\
\hline En_able & $\mathrm{R}$ & $\begin{array}{l}\text { Interface board latch setting corre- } \\
\text { sponding to the desired output board. } \\
\text { ( } 61432 \text { for reference, } 57336 \text { for variable) }\end{array}$ & $\begin{array}{l}\text { Amplitude } \\
\text { Cor_dac }\end{array}$ \\
\hline Enable & $\mathrm{R}$ & $\begin{array}{l}\text { Value set up in Calibrate and used in } \\
\text { Measure in calls to Amplitude (see } \\
\text { En_able above). }\end{array}$ & Measure \\
\hline Enable & $\mathrm{R}$ & See En_able above.Offset_zero & \\
\hline Entered & I & $\begin{array}{l}\text { Flag indicating that the "ENTER" key was } \\
\text { hit. This results in the accumulated } \\
\text { data in NumS to be transferred to ValueS } \\
\text { or Value. (see Process_key code) }\end{array}$ & Process_key \\
\hline Error & $\mathrm{R}$ & The measured error of a particular trial & Measure \\
\hline Error $\$(1: 2,1: 6)[7]$ & $\$$ & $\begin{array}{l}\text { String array used to print the formatted } \\
\text { wattmeter errors at the end of a test } \\
\text { point run. }\end{array}$ & Digit \\
\hline Ex & I & $\begin{array}{l}\text { Used in TABXY statements for displaying } \\
\text { field data. Ex is computed in the sub- } \\
\text { routine, Ex_why_vals, within Digit. }\end{array}$ & Digit \\
\hline $\mathrm{F}$ & $\mathrm{R}$ & $\begin{array}{l}\text { Generator waveform output frequency. } \\
\text { Manipulated by Synth_load. }\end{array}$ & Main \\
\hline F_scale & $\mathrm{R}$ & $\begin{array}{l}\text { Full scale of either voltage or current } \\
\text { allowable by the } 18 \text {-bit mdac (U9). }\end{array}$ & $\begin{array}{l}\text { Amplitude } \\
\text { Cor_dac }\end{array}$ \\
\hline F_unitS[3] & $\$$ & $\begin{array}{l}\text { Generator output frequency units. Com- } \\
\text { puted by Synth_load and used in Status. }\end{array}$ & Main \\
\hline F5 & $\mathrm{R}$ & $\begin{array}{l}\text { Intermediate variable used in the calcu- } \\
\text { lation of the synthesizer configuration } \\
\text { codes. }\end{array}$ & Synth_load \\
\hline F6 & $\mathrm{R}$ & See F5 above. & Synth_load \\
\hline F6_range & $\mathrm{R}$ & $\begin{array}{l}\text { Intermediate variable used in the calcu- } \\
\text { lation of the synthesizer configuration } \\
\text { codes. }\end{array}$ & Synth_load \\
\hline F7 & $\mathrm{R}$ & See F6_range above. & Synth_load \\
\hline F8 & $\mathrm{R}$ & See F6_range above. & Synth_load \\
\hline F9 & $\mathrm{R}$ & See F6_range above. & Synth_load \\
\hline Filename $\$[30]$ & $\$$ & $\begin{array}{l}\text { Defines the file to which the error data } \\
\text { is written. }\end{array}$ & Measure \\
\hline Finished & I & $\begin{array}{l}\text { Exit flag used in the subroutine Print_ } \\
\text { message. }\end{array}$ & Digit \\
\hline First_time & I & $\begin{array}{l}\text { If First time }=1 \text { on entry then Offset } \\
\text { zero will call Measure with Row }=0 \text {, which } \\
\text { results in the meter being initialized } \\
\text { before being used. }\end{array}$ & Offset_zero \\
\hline First_time & I & $\begin{array}{l}\text { If First time }=1 \text { then the subroutine } \\
\text { Next_value ignores the variable, Settle_ } \\
\text { time. }\end{array}$ & Measure \\
\hline
\end{tabular}


Found

Fr_eq

Freq_range

Full_scale

Func_buf(*)

FunctionS

Function $\$[9]$

G3

G4

G5

G6

G7

G9

Gain

Gain

Gain\$

$\operatorname{Gar} \$[80]$

Graphics\$[2]

Ham_flag

Highlight\$[1]
$\mathrm{R} \quad$ Loop exit condition in the subroutine Read_meter within Measure.

$\mathrm{R} \quad$ The generator's waveform output freq.

$\mathrm{R} \quad$ Used to compute the synthesizer board's proper range setting.

$\mathrm{R}$ The full scale value of the parameter being measured.

B Input parameter that references either the Coarse_ref(*) or Coarse_var(*) INTEGER buffers.

\$ Input parameter that determines which function will be loaded into the appropriate memory channel.

\$ Local variable that contains a slightly altered form of the parameter, Choice\$.

$\mathrm{R}$ Intermediate variable used in the calculation of the synthesizer configuration codes.

R See G3 above.

R See G3 above.

$\mathrm{R}$ Intermediate variable used in the calculation of the memory board counter increment.

R See G6 above.

R See G3 above.

$\mathrm{R} \quad$ Used in the calculation of $\mathrm{X} 1, \mathrm{X} 2$ and $\mathrm{X} 3$. Gain $=40$ if En able $=61432$ and Ref amp > $7.07 \mathrm{Vrms},=0$ otherwise.

$\mathrm{R} \quad$ Used in the calculation of errors. $=40$ if the measurements are taken at the output of the Voltage amplifier, $=0$ otherwise.

$\$ \quad$ Used in the Interactive I/O group of subprograms for display purposes. Gain $=$ "GAIN" always.

Used for display purposes in the routine Date set.

Non ASCII key sequence output to the keyboard that sets the crt into graphics mode.

Signals the subroutine, Int_service, that the meter of interest has sent the reading.

\$ Non ASCII key sequence output to the keyboard that sets the crt into reverse video mode.
Measure

Ivd

Main

Synth_load

Measure

Out_put

Init

Main

Init

Cor_dac

Synth_load

Synth_load

Synth_load

Set_inc

Set_inc

Synth load

Amplitude

Gain

Measure

Main

Main

Main

Measure

Digit 
Name

Home\$[2]

How_much\$[3]

I\$[12]

Icap

Illegal

Image\$[25]

Inc

Inc_rement

Index

Ins

Intercept

Interval

Inverse

Ires

It_rep_num

Key\$

Knob_activate

L2_1ss

L2_mss

Lat_code
Type

Description

$\$$

Non ASCII key sequence output to the keyboard that positions the cursor at the home position.

$\$ \quad$ String used as the Cor dac input parameter, Mode\$. See Mode\$ for details.

$\$ \quad$ Storage for the image string used to print the applied current and power factor on the test results.

$\mathrm{R} \quad$ Intermediate variable used to calculate the Ivd settings, Civd and Rivd.

I Flag indicating that rows 3 and 4 have been left in an illegal state within the subprogram Digit.

$\$ \quad$ Storage for the image string used to display the phase and phase units.

$\mathrm{R}$ The desired counter increment. In certain instances, Inc may be set to zero.

$\mathrm{R}$ Storage for the counter increment. Inc may be restored with Inc_rement.

I Keeps track of the index to Message $\$$ the subroutine, Print message.

R Nominal scale for the current waveform where Ins $=$ Applied/Range. Used in the subroutine Range_correct for wattmeter error calculations.

$\mathrm{R} \quad$ Input parameter for determining various correction factors from linear correction curves.

$\mathrm{R}$ The incremental change (in terms of percent of full scale ) that is added to the parameter of interest at each successive test point.

Flag indicating whether the field should be displayed in inverse video. Intermediate variable used to calculate the Ivd settings, Civd and Rivd.

Counter for the number of measurement groups to be taken at each test point.

$\$ \quad$ Used to hold the contents of the KBD buffer for processing.

Flag that enables the knob for changing the contents of the fields.

$\mathrm{R} \quad$ Least significant slice of the memory board's variable counter increment latch.

$\mathrm{R} \quad$ Most significant slice of the memory board's variable counter increment latch.

R Enable code for the Switch Box's various relay latches.
Found In:

Main

Offset_zero

Digit

Ivd

Main

Adj_phase

Main

Main

Digit

Digit

Cor_dac Amplitude

Measure

Digit

Ivd

Digit

Process_key

Digit

Main

Main

Switch 


\begin{tabular}{|c|c|c|c|}
\hline$\underline{\text { Name }}$ & Type & Description & Found In: \\
\hline Lat_u6 & $\mathrm{R}$ & $\begin{array}{l}\text { Input parameter which contains the last } \\
6 \text {-bits of the latch U6 on the output } \\
\text { board. Intended to keep track of gain/ } \\
\text { linearity mdac settings. }\end{array}$ & $\begin{array}{l}\text { Cor_dac } \\
\text { Amplitude }\end{array}$ \\
\hline Lat2 & $\mathrm{R}$ & $\begin{array}{l}\text { Used for combining } \mathrm{L} 2 \text { mss and L2_lss } \\
\text { into one word and restoring latch } 2 \text { on } \\
\text { memory board. }\end{array}$ & Cnt_vals \\
\hline Lat3 & $\mathrm{R}$ & $\begin{array}{l}\text { Used for computing and loading the new } \\
\text { memory board counter increment. }\end{array}$ & Cnt_vals \\
\hline Latch & I & 8 -bit relay data word. $0<=$ Latch $<=255$ & Switch \\
\hline Lead_or_lag\$[2] & $\$$ & $\begin{array}{l}\text { Used for error data printing purposes } \\
\text { and specifies the phase relation of the } \\
\text { two waveforms. }\end{array}$ & Digit \\
\hline Limit & $\mathrm{R}$ & $\begin{array}{l}\text { The limit (in Ppm) of the allowable } \\
\text { errors that will be accepted and pro- } \\
\text { cessed. }\end{array}$ & Measure \\
\hline Linear\$ & $\$$ & $\begin{array}{l}=\text { "LINEAR" always. Used for display } \\
\text { purposes in the Cor_dac subprogram. }\end{array}$ & Main \\
\hline Load_code & $\mathrm{R}$ & $\begin{array}{l}\text { Input parameter of various routines } \\
\text { which is used ultimately by Out_put to } \\
\text { decide which memory channel(s) to load. } \\
=9: \text { Load channel } 1 \text { (ref) only. } \\
=6: \text { Load channel } 2 \text { (var) only. } \\
=12: \text { Load both channels. }\end{array}$ & $\begin{array}{l}\text { Adj_phase } \\
\text { Change_phase } \\
\text { Init, Out_put }\end{array}$ \\
\hline Meas_str $\$(1: 8,1: 6,0: 2)$ & $\$$ & $\begin{array}{l}\text { String values initialized in the mainMain, } \\
\text { program and used by Digit to display } \\
\text { the various wattmeter testing parameters. } \\
\text { See section } 3.5 .1 \text { for contents. }\end{array}$ & Digit \\
\hline Meas_vals(1:9,1:6) & $\mathrm{R}$ & $\begin{array}{l}\text { Storage for specific error computation } \\
\text { values used for a single test point. } \\
\text { See section } 3.5 .4 \text { for contents. }\end{array}$ & Digit \\
\hline Message & $\mathrm{R}$ & $\begin{array}{l}\text { Flag to avoid incorrect keystroke } \\
\text { acceptance. For a list of meanings, see } \\
\text { the code. }\end{array}$ & Process_key \\
\hline Message $\$(1: 5)[85]$ & $\$$ & $\begin{array}{l}\text { Used in the Print_message subroutine to } \\
\text { store the printout message data. }\end{array}$ & Digit \\
\hline Mode\$ & $\$$ & $\begin{array}{l}\text { Input parameter which determines the } \\
\text { initial behavior of the Interactive I/O } \\
\text { Routines. See the code for further } \\
\text { explanation. }\end{array}$ & $\begin{array}{l}\text { Adj_phase } \\
\text { Amplitude } \\
\text { Cor_dac }\end{array}$ \\
\hline New_line & $\mathrm{R}$ & $\begin{array}{l}\text { Flag used in the Print_message routine } \\
\text { to indicate the starting of a new line. }\end{array}$ & Digit \\
\hline New_range & I & $\begin{array}{l}\text { Used in the subroutine Check_range to } \\
\text { insure that the applied value is not out } \\
\text { of the Hamburger's input range. }\end{array}$ & Measure \\
\hline Next_col & I & $\begin{array}{l}\text { Used in the subroutine Next_field to } \\
\text { indicate the column of the next field. }\end{array}$ & Digit \\
\hline
\end{tabular}


Name

Next_quotient

Next_row

No_cntr

No_dvm

Num

Num\$[160]

Num_ber

Num_of_readings

Num_of_reps

Number

Number

Offset

Offset\$

Offst

Old_range

Old_value

Omega

Only_1st_time

Output_down
Found In:

R Exit condition for the subprogram.

When Next_quotient $=0$, the subprogram terminates.

I Used in the subroutine Next_field to indicate the row of the next field.

I Flag to indicate whether or not a counter reading is to be taken for the specific meter.

I Flag to indicate whether or not a dvm reading is to be taken for the specific meter.

I Count specifier of the number of readings to be taken of each MUT in a measurement group.

$\$ \quad$ Used by any subprogram which calls Process_key. Num\$ is the storage for the keyboard input processed by Process key.

$\mathrm{R}$ Input parameter for Process_key in the subroutine Key, which processes keyboard input for the number of measurement iterations and groups.

The number of readings to be taken at each Guildline setting.

The number of readings to be averaged for each test point.

$\mathrm{R} \quad$ Storage for each dvm reading.

$\mathrm{R}$ The value in the subroutine $\mathrm{D}_{-}$to $\mathrm{b}$ which is converted into a binary string.

$\mathrm{R}$ Input parameter for the call to Measure. It represents the dc offset of the channel of interest.

$\$ \quad=$ "OFFSET" always. Used for display purposes in the Cor_dac subprogram.

$\mathrm{R}$ The phase (in degrees) of the reference channel waveform.

I Used in the subroutine Check_range to insure that the applied value is not out of the Hamburger's input range.

$\mathrm{R} \quad$ Used in the differential non linearity calibrations for calculating the differential reading values.

$\mathrm{R}$ Intermediate variable used to calculate the Ivd settings, Civd and Rivd.

Used in the subroutine Key for processing the number of measurement iterations and groups.

R Flag used to inhibit the V-amp from being enabled at unnecessary times.
Dec to bin

Digit

Digit

Digit

Digit

Main

Digit

Guildline

Measure

Digit

Main

Offset_zero

Main

Main

Measure

Measure

Ivd

Digit

Main, Enable 


\begin{tabular}{|c|c|c|c|}
\hline Name & Type & Description & Found In: \\
\hline$P_{-}$factor & $\mathrm{R}$ & $\begin{array}{l}\text { Storage for the present applied power } \\
\text { power factor. Used for printing purposes. }\end{array}$ & Digit \\
\hline P_of_fs_limit & $\mathrm{R}$ & $\begin{array}{l}\text { The limit (in terms of full scale) of } \\
\text { the incremented calibration value. }\end{array}$ & Measure \\
\hline Page & I & Menu page indicator. & Calibrate \\
\hline Page1_row & I & $\begin{array}{l}\text { Storage for the row that the first page } \\
\text { menu was left on. }\end{array}$ & Calibrate \\
\hline Percent_of_fs & $\mathrm{R}$ & $\begin{array}{l}\text { Multiplier (in terms of full scale) used } \\
\text { to determine the applied calibration value. }\end{array}$ & Measure \\
\hline Phase\$ & $\$$ & $\begin{array}{l}=\text { "PHASE" always. Used for display } \\
\text { purposes in the Adj_phase subprogram. }\end{array}$ & Main \\
\hline Phaz & $\mathrm{R}$ & $\begin{array}{l}\text { The phase (in degrees) of the variable } \\
\text { channel waveform. }\end{array}$ & $\begin{array}{l}\text { Ivd } \\
\text { Main }\end{array}$ \\
\hline Ppm & $\mathrm{R}$ & $\begin{array}{l}\text { The error (in Ppm of } 120 \mathrm{Vrms} \text { ) of the } \\
\text { reference channel waveform. }\end{array}$ & Guildline \\
\hline Ppm & $\mathrm{R}$ & $\begin{array}{l}\text { The correction (in Ppm of reading) to be } \\
\text { added to the computed value. }\end{array}$ & $\begin{array}{l}\text { Cor_dac } \\
\text { Amplitude }\end{array}$ \\
\hline Ppm & $\mathrm{R}$ & $\begin{array}{l}\text { The error (in Ppm of full scale or read- } \\
\text { ing, depending on the row) of the meas- } \\
\text { ured wattmeter output. }\end{array}$ & Digit \\
\hline Quotient & $\mathrm{R}$ & $\begin{array}{l}\text { Input parameter of the recursive } \\
\text { routine which is divided by } 2 \text { until a } \\
\text { quotient of zero is found. }\end{array}$ & Dec_to_bin \\
\hline $\mathrm{R}$ & $\mathrm{R}$ & $\begin{array}{l}\text { Intermediate variable used to calculate } \\
\text { the Ivd settings, Civd and Rivd. }\end{array}$ & Ivd \\
\hline R_func $\$[8]$ & $\$$ & $\begin{array}{l}\text { String used for display purposes which } \\
\text { identifies the present reference channel } \\
\text { waveform type. }\end{array}$ & Main \\
\hline R_intercept & $\mathrm{R}$ & $\begin{array}{l}\text { Intercept of the reference channel's } \\
\text { linear gain correction curve. }\end{array}$ & Main \\
\hline R_rms & $\mathrm{R}$ & $\begin{array}{l}\text { The computed Rms value of a } 1 \mathrm{Vp} \text { refer- } \\
\text { ence channel waveform }\left(0<=R_{-} \text {rms }<=1\right) \text {. }\end{array}$ & Main \\
\hline R_slope & $\mathrm{R}$ & $\begin{array}{l}\text { Slope of the reference channel's linear } \\
\text { gain correction curve. }\end{array}$ & Main \\
\hline R_u9_offst & $\mathrm{R}$ & $\begin{array}{l}\text { The dc offset setting for the reference } \\
\text { channel's amplitude dac (U9 on artwork). } \\
\text { This value is set in Cor_dac's "LINEAR- } \\
\text { ITY" mode during output board adjustment } \\
\text { and should not be changed between adjust- } \\
\text { ments. }\end{array}$ & Main \\
\hline R_unit\$[3] & $\$$ & $\begin{array}{l}\text { String used for display purposes which } \\
\text { identifies the present reference channel } \\
\text { amplitude units }(\mathrm{V}, \mathrm{mV} \text {, etc). }\end{array}$ & Main \\
\hline Rad & $\mathrm{R}$ & $\begin{array}{l}\text { Intermediate variable used to calculate } \\
\text { the Ivd settings, Civd and Rivd. }\end{array}$ & Ivd \\
\hline Range & $\mathrm{R}$ & $\begin{array}{l}\text { Value used for display purposes to } \\
\text { determine the proper unit string for the } \\
\text { parameter being manipulated. }\end{array}$ & $\begin{array}{l}\text { Adj_phase } \\
\text { Amplitude } \\
\text { Cor_dac }\end{array}$ \\
\hline
\end{tabular}


Name

Range_changed

Rate

Reading\$[10]

$\operatorname{Real}\left({ }^{*}\right)$

Real_ref(2048)

Real_var(2048)

RefS

Ref_amp

Ref_c1

Ref_diff(2048)

Ref_gain

Remainder

Reset_delay

Resistor_corr

Rivd
Found In:

Digit

Flag indicating that at least one range field in the Digit display has been

Main changed, which signals the subprogram, Next_col (within Body), to restore the proper ranges into the Meas_str $\$(7, X, 0)$ locations.

$\mathrm{R} \quad$ Used by the interactive I/O subprograms to determine the rate at which the parameter of interest is changed by the knob, function keys or keyboard input.

\$ Hamburger K2004 input variable. Since the Hamburger outputs BCD string data, a string input variable must be used. This string is then parsed to extract the numeric and decimal point information and transferred to Value.

$\mathrm{R}$ Init input parameter that corresponds to Real_ref(*) or Real_var(*) depending on which channel is to be loaded.

$\mathrm{R} \quad$ Contains the $2048 \mathrm{REAL}$ function values which are then combined with the values in Ref diff(*) and loaded into the INTEGER buffer Coarse_ref(2048).

R Contains the 2048 REAL function values which are then combined with the values in Var_diff( $\left(^{*}\right)$ and loaded into the INTEGEER buffer Coarse_var(2048).

$\$ \quad$ ="REFERENCE" always. Used for display purposes.

$\mathrm{R} \quad$ Contains the rms value of the reference channel waveform amplitude.

R Global storage for the last 2-bits of the reference channel amplitude dac setting (U9 on Output Board).

R See Real ref(2048) above.

$\mathrm{R} \quad$ Ppm of reading gain correction calculated by both Amplitude and Cor_dac using Ref_amp, $R_{-}$slope and $\mathrm{R}$ _intercept.

$\mathrm{R}$ Intermediate variable used to determine the equivalent binary string representation of the input parameter, Quotient. ON DELAY parameter used to reset the Hamburger K2004's interface box.

$\mathrm{R} \quad$ Used in the subroutine Dvm_read to correct the dvm reading of the wattmeter's analog output across the standard resistor. $\mathrm{R} \quad$ The setting of the resistive Ivd.
Amplitude

Compliance

Cor_dac

Meas

Init

Main

Main

Amplitude

Cor_dac

Main

Main

Amplitude

Cor_dac

Main

Main

Main

Dec_to_bin

Meas

Digit

Ivd, Main 


\begin{tabular}{|c|c|c|c|}
\hline$\underline{\text { Name }}$ & Type & Description & Found In: \\
\hline Rms_array(2048) & $\mathrm{R}$ & $\begin{array}{l}\text { Used in the subroutine Step_num to cal- } \\
\text { culate the rms amplitude value of the } \\
\text { chosen waveform from discrete steps. }\end{array}$ & Main \\
\hline Rms_volts & $\mathrm{R}$ & $\begin{array}{l}\text { Assigned to either R_rms or V_rms } \\
\text { depending on En_able. See R_rms or } \\
\text { V_rms for an explanation of its use. }\end{array}$ & $\begin{array}{l}\text { Amplitude } \\
\text { Cor_dac }\end{array}$ \\
\hline Ro_intercept & $\mathrm{R}$ & $\begin{array}{l}\text { Intercept of the reference channel's } \\
\text { linear dc offset correction curve. }\end{array}$ & Main \\
\hline Ro_slope & $\mathrm{R}$ & $\begin{array}{l}\text { Slope of the reference channel's linear } \\
\text { dc offset correction curve. }\end{array}$ & Main \\
\hline Row & I & $\begin{array}{l}\text { Used in various routines to keep track } \\
\text { of the display row of that routine. } \\
\text { Also, Row is used to reference various } \\
\text { parameter arrays. }\end{array}$ & $\begin{array}{l}\text { Calibrate } \\
\text { Digit } \\
\text { Measure }\end{array}$ \\
\hline Row_index & I & $\begin{array}{l}\text { Index to the first dimension of Calib_ } \\
\text { val\$ }(12,4)[30] \text {. See section } 3.4 .3 \text {. } \\
\text { Set according to the page of the menu. }\end{array}$ & Calibrate \\
\hline Row_max & I & $\begin{array}{l}\text { Maximum number of columns allowable in } \\
\text { the Digit subprogram. }\end{array}$ & Main \\
\hline Scale & $\mathrm{R}$ & $\begin{array}{l}\text { The variable Change is scaled by this } \\
\text { value according to Sel_ect. See Change } \\
\text { and Sel_ect for details. }\end{array}$ & Adj_phase \\
\hline Scale $\$[12]$ & $\$$ & $\begin{array}{l}\text { String identifying the value of scale, } \\
\text { above. Scale } \$="(P A R T S / 2048) " \text { or } \\
\text { Scale } \$=" \quad \text { (RAD) " depending on the } \\
\text { value of Sel_ect. }\end{array}$ & Adj_phase \\
\hline Scale_factor & $\mathrm{R}$ & $\begin{array}{l}\text { Used in the subroutine Error_process to } \\
\text { scale the nominal value of what is being } \\
\text { measured according to the location of the } \\
\text { measurement point, which is expected to } \\
\text { be either the input or output of the } \\
\text { amplifier. }\end{array}$ & Measure \\
\hline Scr_mat $(1: 8,1: 6)$ & I & $\begin{array}{l}\text { Array used to keep track of the indexes } \\
\text { to the third dimension of Meas_str\$. }\end{array}$ & Main \\
\hline $\mathrm{Sec}$ & I & $\begin{array}{l}\text { Used by the subroutine Time left to dis- } \\
\text { play the time remaining until completion } \\
\text { of the Init subprogram. }\end{array}$ & Init \\
\hline Sel_ect & I & $\begin{array}{l}\text { Flag indicating the phase resolution } \\
\text { mode setting. For fine resolution, Sel_- } \\
\text { ect }=2 \text {, and for coarse, Sel_ect }=1 \text {. }\end{array}$ & Main \\
\hline Sel_ect\$[6] & $\$$ & $\begin{array}{l}\text { This display string = "FINE " or } \\
\text { "COARSE" depending on the value of Sel_- } \\
\text { ect. }\end{array}$ & Adj._phase \\
\hline Ser_pol & I & $\begin{array}{l}\text { Used in various measurement routines to } \\
\text { store an interface serial poll in the } \\
\text { event of a device service request inter- } \\
\text { rupt. }\end{array}$ & $\begin{array}{l}\text { Digit } \\
\text { Measure }\end{array}$ \\
\hline
\end{tabular}




\begin{tabular}{|c|c|c|c|}
\hline Name & Type & Description & Found In: \\
\hline Setting_number & I & $\begin{array}{l}\text { Counter (1-4) used for display and cal- } \\
\text { culation purposes that corresponds to the } \\
\text { number of Guildline settings. }\end{array}$ & Guildline \\
\hline Settle_time & I & $\begin{array}{l}\text { Guildline TE settling time after a } \\
\text { setting change. }\end{array}$ & Guildline \\
\hline Settle_time & I & Settling time of a new applied value. & Measure \\
\hline Settled & I & $\begin{array}{l}\text { Flag indicating that the Guildline TE } \\
\text { has settled. }\end{array}$ & Guildline \\
\hline Sine & $\mathrm{R}$ & $\begin{array}{l}\text { Intermediate variable used to calculate } \\
\text { the Ivd settings, Civd and Rivd. }\end{array}$ & Ivd \\
\hline Slope & $\mathrm{R}$ & $\begin{array}{l}\text { Input parameter containing the slope of } \\
\text { the linear correction curve relevant to } \\
\text { the value being changed. }\end{array}$ & $\begin{array}{l}\text { Cor_dac } \\
\text { Amplitude }\end{array}$ \\
\hline Srq & I & $\begin{array}{l}\text { Serial request bit of the meter being } \\
\text { used that is set according to the } \\
\text { Calib_val } \$(12,4)[30] \text { field, Device\$. }\end{array}$ & Measure \\
\hline String\$ & s & $\begin{array}{l}\text { Accumulation for the resultant binary } \\
\text { equivalent string. }\end{array}$ & Dec_to_bin \\
\hline String\$[160] & $\$$ & $\begin{array}{l}\text { Input variable for the Hamburger K2004's } \\
\text { configuration string. }\end{array}$ & Measure \\
\hline Temp & $\mathrm{R}$ & $\begin{array}{l}\text { Storage for the initial phase value upon } \\
\text { entry to the subprogram. }\end{array}$ & Adj_phase \\
\hline Temp\$ & $\$$ & Used to clear the keyboard buffer. & Change_phase \\
\hline Temp_v & $\mathrm{R}$ & $\begin{array}{l}\text { Storage for the initial value upon entry } \\
\text { to the subprogram. }\end{array}$ & $\begin{array}{l}\text { Amplitude } \\
\text { Cor_dac }\end{array}$ \\
\hline TimeS & $\$$ & $\begin{array}{l}\text { Display variable used in the subroutine } \\
\text { Time;set. }\end{array}$ & Main \\
\hline Tmp_col & I & Temporary storage for the display column & Digit \\
\hline Tmp_row & I & Temporary storage for the display row. & Digit \\
\hline Top_row & I & Top row of the menu. & Calibrate \\
\hline True_rms & $\mathrm{R}$ & $\begin{array}{l}\text { Calculated using matrix operations. See } \\
\text { R_rms or V_rms for details. }\end{array}$ & Init \\
\hline U1 & I & $\begin{array}{l}\text { Used by Switch to decide which Switch } \\
\text { Box latch to enable. }\end{array}$ & Main \\
\hline U2_u3I & & See U1 above. & Main \\
\hline $\mathrm{U} 4 \overline{\mathrm{I}}$ & & See U1 above. & Main \\
\hline Unit\$ & $\$$ & $\begin{array}{l}\text { Unit display string that is set accord- } \\
\text { ing to the scaled output value, Vol_tage } \\
\text { or Angle. }\end{array}$ & $\begin{array}{l}\text { Adj_phase } \\
\text { Amplitude } \\
\text { Cor_dac }\end{array}$ \\
\hline V\$[7] & $\$$ & $\begin{array}{l}\text { Used to print the present voltage range } \\
\text { setting on the test results printout. }\end{array}$ & Digit \\
\hline V_amp & I & $\begin{array}{l}\text { Flag indicating whether or not the V-amp } \\
\text { is enabled or not. }\end{array}$ & Main \\
\hline$V_{-}$func(2048) & $\mathrm{R}$ & $\begin{array}{l}\text { Intermediate REAL array used in the cal- } \\
\text { culation of the new Coarse_var array. }\end{array}$ & Change_phase \\
\hline V_funcS[8] & $\$$ & $\begin{array}{l}\text { String used for display purposes which } \\
\text { identifies the present variable channel } \\
\text { waveform type. }\end{array}$ & Main \\
\hline
\end{tabular}


Name

$V_{\text {_intercept }}$

V_rms

$\mathrm{V}_{-}$slope

V_u9_offst

V_unit\$[3]

Value

Value

Value

Value\$

Var\$

Var_amp

Var_c1

Var_diff(2048)

Var_gain

Vns

Vo_intercept

Vo_lts

Vo_slope

Vol_string\$[20]

Voltage
Type

$\mathrm{R}$

R

$\mathrm{R}$

R

\section{$\$$}

$\mathrm{R}$

R

R

$\$$

$\$$

R

$\mathrm{R}$

$\mathrm{R}$
$\mathrm{R}$

$\mathrm{R}$

$\mathrm{R}$

$\mathrm{R}$

$\$$

R
$\mathrm{R} \quad$ Scaled version of the parameter being

$\mathrm{R} \quad$ Slope of the variable channel's

Intercept of the variable channel's

linear gain correction curve.

\section{See R rms above.}

Slope of the variable channel's linear gain correction curve.

The dc offset setting for the variable channel's amplitude dac (U9 on artwork).

This value is set in Cor_dac's "LINEAR-

ITY" mode during output board adjustment and should not be changed between adjustments.

\section{String used for display purposes which} identifies the present variable channel amplitude units ( $\mathrm{V}, \mathrm{mV}$, etc).

$\mathrm{R}$ Storage for numeric only data when an ENTER key is hit.

\section{Input variable for dvm error readings.}

Value returned from a call to Measure.

Num $\$$ is accumulated here until an ENTER key is hit.

$=$ "VARIABLE" always. Used for display purposes.

Contains the rms value of the variable channel waveform amplitude.

R Global storage for the last 2-bits of the variable channel amplitude dac setting (U9 on Output Board).

See Real_var(2048) above. $\mathrm{Ppm}$ of reading gain correction calculated by both Amplitude and Cor_dac using Var_amp, V_slope and V_intercept.

$\mathrm{R}$ Nominal scale for the voltage waveform where Vns=Applied/Range. Used in the subroutine Range_correct for wattmeter error calculations.

Intercept of the variable channel's linear dc offset correction curve. manipulated used for display purposes. See Voltage below. linear dc offset correction curve. Holds the string representation of the present 18-bit amplitude dac setting. Un-scaled version of the parameter being manipulated used for display purposes. See Vo_lts above.
Found In:

Main

Main

Main

Main

Main

Cor_dac

Process_key

Synth_load

Guildline

Measure

Digit

Process_key

Main

Main

Main

Main

Main

Digit

Main

Amplitude

Cor_dac

Main

Amplitude

Amplitude

Cor_dac 


\section{$\underline{\text { Name }}$}

What_was_meas\$[3] $\$$

Why

Within_cor_dacS

$\mathrm{X}$

$\mathrm{X}$

$\mathrm{X} 1$

$\mathrm{X} 2$

$\mathrm{X} 2$

$\mathrm{X} 3$

$\mathrm{Y}$

Z
Type

Description

$\$ \quad$ String printed along with the errors to identify the test that was performed.

I Used in TABXY statements for displaying field data. Why is computed in the subroutine, Ex_why_vals, within Digit.

$\$$ If Offset zero is called with this string $=" \overline{P R I N T} I$, then the Print_volt subroutine within Cor_dac will be called for every iteration of Öffset_zero.

$\mathrm{R} \quad$ Used to clear the keyboard buffer.

$\mathrm{R} \quad$ Used in the subroutine Key_in to protect against superfluous BACKSPACE entries.

$\mathrm{R}$ Intermediate variable used in the calculation of the 18-bit amplitude dac word.

$\mathrm{R} \quad$ See X1 above.

$\mathrm{R} \quad$ The 8-bit correction dac setting.

$\mathrm{R} \quad$ See X1 above.

I Loop counter for wattmeter measurements.

$\mathrm{R} \quad$ Value used for debugging purposes to determine the actual 24-bit Ivd setting.
Found In:

Digit

Digit

Offset_zero

Amplitude

Digit

Amplitude

Cor_dac

Amplitude

Digit

Ivd 


\begin{tabular}{ll}
\hline NIST-114A & U.S. DEPARTMENT OF COMMERCE \\
REV. 3-89) & NATIONAL INSTITUTE OF STANDARDS AND TECHNOLOGY
\end{tabular}

\section{BIBLIOGRAPHIC DATA SHEET}

1. PUBLICATION OR REPORT NUMBER NIST/TN-1281

2. PERFoRMING ORGANIZATION REPORT NUMBER

3. PUBLication DATE

August 1990

TITLE AND SUBTITLE

\section{THE NIST DIGITALLY-SYNTHESIZED POWER CALIBRATION SOURCE}

AUTHOR(S)

N.M. O1dham, O.B. Laug, B.C. Waltrip, and R.H. Palm

PERFORMING ORGANIZATION (IF JOINT OR OTHER THAN NIST, SEE INSTRUCTIONS)

U.S. DEPARTMENT OF COMMERCE

NATIONAL INSTITUTE OF STANDARDS AND TECHNOLOGY

GAITHERSBURG, MD 20899

SPONSORING ORGANIZATION NAME AND COMPLETE ADDRESS (STREET, CITY, STATE, ZIP)

Same as item \#6

\section{SUPPLEMENTARY NOTES}

DOCUMENT DESCRIBES A COMPUTER PROGRAM; SF-185, FIPS SOFTWARE SUMMARY, IS ATTACHED.

ABSTRACT (A 200-WORD OR LESS FACTUAL SUMMARY OF MOST SIGNIFICANT INFORMATION. IF DOCUMENT INCLUDES A SIGNIFICANT BIBLIOGRAPHY OR LITERATURE SURVEY, MENTION IT HERE.)

A digitally-synthesized source of "phantom" power for calibrating electrical power and energy meters is described. Independent sources of voltage, current, and phase angle are programmable between 0-240 volts, 0-5 amperes, and 0-360 degrees, respectively. The uncertainty of the active and reactive power is estimated to be within t100 ppm of the full scale apparent power (volt-amperes).

KEY WORDS (6 TO 12 ENTRIES; ALPHABETICAL ORDER; CAPITALIZE ONLY PROPER NAMES; AND SEPARATE KEY WORDS BY SEMICOLONS)

calibration; digital waveform synthesis; power measurement; TDM wattmeter; transconductance amplifier; voltage amplifier; wattmeter; watt-hour meter

AVAILABILITY

$\mathrm{X}$ UNLIMITED

FOR OFFICIAL DISTRIBUTION. DO NOT RELEASE TO NATIONAL TECHNICAL INFORMATION SERVICE (NTIS).

ORDER FROM SUPERINTENDENT OF DOCUMENTS, U.S. GOVERNMENT PRINTING OFFICE, WASHINGTON, DC 20402.

ORDER FROM NATIONAL TECHNICAL INFORMATION SERVICE (NTIS), SPRINGFIELD, VA 22161.
14. NUMBER OF PRINTED PAGES

6,2

15. PRICE 

Journal of Research of the National Institute of Standards and Technology-Reports NIST research and development in those disciplines of the physical and engineering sciences in which the Institute is active. These include physics, chemistry, engineering, mathematics, and computer sciences. Papers cover a broad range of subjects, with major emphasis on measurement methodology and the basic technology underlying standardization. Also included from time to time are survey articles on topics closely related to the Institute's technical and scientific programs. Issued six times a year.

\section{Nonperiodicals}

Monographs-Major contributions to the technical literature on various subjects related to the Institute's scientific and technical activities.

Handbooks-Recommended codes of engineering and industrial practice (including safety codes) developed in cooperation with interested industries, professional organizations, and regulatory bodies.

Special Publications-Include proceedings of conferences sponsored by NIST, NIST annual reports, and other special publications appropriate to this grouping such as wall charts, pocket cards, and bibliographies.

Applied Mathematics Series-Mathematical tables, manuals, and studies of special interest to physicists, engineers, chemists, biologists, mathematicians, computer programmers, and others engaged in scientific and technical work.

National Standard Reference Data Series-Provides quantitative data on the physical and chemical properties of materials, compiled from the world's literature and critically evaluated. Developed under a worldwide program coordinated by NIST under the authority of the National Standard Data Act (Public Law 90-396). NOTE: The Journal of Physical and Chemical Reference Data (JPCRD) is published quarterly for NIST by the American Chemical Society (ACS) and the American Institute of Physics (AIP). Subscriptions, reprints, and supplements are available from ACS, 1155 Sixteenth St., NW., Washington, DC 20056.

Building Science Series-Disseminates technical information developed at the Institute on building materials, components, systems, and whole structures. The series presents research results, test methods, and performance criteria related to the structural and environmental functions and the durability and safety characteristics of building elements and systems.

Technical Notes-Studies or reports which are complete in themselves but restrictive in their treatment of a subject. Analogous to monographs but not so comprehensive in scope or definitive in treatment of the subject area. Often serve as a vehicle for final reports of work performed at NIST under the sponsorship of other government agencies.

Voluntary Product Standards-Developed under procedures published by the Department of Commerce in Part 10, Title 15, of the Code of Federal Regulations. The standards establish nationally recognized requirements for products, and provide all concerned interests with a basis for common understanding of the characteristics of the products. NIST administers this program as a supplement to the activities of the private sector standardizing organizations.

Consumer Information Series-Practical information, based on NIST research and experience, covering areas of interest to the consumer. Easily understandable language and illustrations provide useful background knowledge for shopping in today's technological marketplace.

Order the above NIST publications from: Superintendent of Documents, Government Printing Office, Washington, DC 20402.

Order the following NIST publications_FIPS and NISTIRs-from the National Technical Information Service, Springfield, VA 22161.

Federal Information Processing Standards Publications (FIPS PUB)-Publications in this series collectively constitute the Federal Information Processing Standards Register. The Register serves as the official source of information in the Federal Government regarding standards issued by NIST pursuant to the Federal Property and Administrative Services Act of 1949 as amended, Public Law 89-306 (79 Stat. 1127), and as implemented by Executive Order 11717 (38 FR 12315, dated May 11, 1973) and Part 6 of Title 15 CFR (Code of Federal Regulations).

NIST Interagency Reports (NISTIR)-A special series of interim or final reports on work performed by NIST for outside sponsors (both government and non-government). In general, initial distribution is handled by the sponsor; public distribution is by the National Technical Information Service. Springfield, VA 22161, in paper copy or microfiche form. 
U.S. Department of Commerce

National Institute of Standards and Technology

(formerly National Bureau of Standards)

Gaithersburg, MD 20899

Official Business

Penalty for Private Use $\$ 300$ 